\title{
Age of air as a diagnostic for transport timescales in global models
}

\author{
Maarten Krol ${ }^{1,2,3}$, Marco de Bruine ${ }^{2}$, Lars Killaars ${ }^{4}$, Huug Ouwersloot ${ }^{5}$, Andrea Pozzer ${ }^{5}$, Yi Yin ${ }^{6, a}$, \\ Frederic Chevallier ${ }^{6}$, Philippe Bousquet ${ }^{6}$, Prabir Patra $^{7}$, Dmitry Belikov ${ }^{8}$, Shamil Maksyutov ${ }^{9}$, Sandip Dhomse $^{10}$, \\ Wuhu Feng ${ }^{11}$, and Martyn P. Chipperfield ${ }^{10,11}$ \\ ${ }^{1}$ Meteorology and Air Quality, Wageningen University, Wageningen, the Netherlands \\ ${ }^{2}$ Institute for Marine and Atmospheric Research, Utrecht University, Utrecht, the Netherlands \\ ${ }^{3}$ Netherlands Institute for Space Research SRON, Utrecht, the Netherlands \\ ${ }^{4}$ Faculty of Science and Engineering, University of Groningen, Groningen, the Netherlands \\ ${ }^{5}$ Max Planck Institute for Chemistry, Mainz, Germany \\ ${ }^{6}$ Laboraroire de Sciences du Climat et de l'Environnement (LSCE), Gif-sur-Yvette, France \\ ${ }^{7}$ Japan Agency for Marine-Earth Science and Technology (JAMSTEC), Yokohama City, Japan \\ ${ }^{8}$ Hokkaido University, Sapporo, Hokkaido, Japan \\ ${ }^{9}$ Center for Global Environmental Research, National Institute for Environmental Studies, Tsukuba, Ibaraki, Japan \\ ${ }^{10}$ School of Earth and Environment, University of Leeds, Leeds, UK \\ ${ }^{11}$ National Centre for Atmospheric Science, University of Leeds, Leeds, UK \\ a now at: Jet Propulsion Laboratory, Pasadena, California, USA
}

Correspondence: Maarten Krol (maarten.krol@wur.nl)

Received: 18 October 2017 - Discussion started: 7 November 2017

Revised: 16 July 2018 - Accepted: 19 July 2018 - Published: 3 August 2018

\begin{abstract}
This paper presents the first results of an age-ofair (AoA) inter-comparison of six global transport models. Following a protocol, three global circulation models and three chemistry transport models simulated five tracers with boundary conditions that grow linearly in time. This allows for an evaluation of the AoA and transport times associated with inter-hemispheric transport, vertical mixing in the troposphere, transport to and in the stratosphere, and transport of air masses between land and ocean. Since AoA is not a directly measurable quantity in the atmosphere, simulations of ${ }^{222} \mathrm{Rn}$ and $\mathrm{SF}_{6}$ were also performed. We focus this first analysis on averages over the period 2000-2010, taken from longer simulations covering the period 1988-2014. We find that two models, NIES and TOMCAT, show substantially slower vertical mixing in the troposphere compared to other models (LMDZ, TM5, EMAC, and ACTM). However, while the TOMCAT model, as used here, has slow transport between the hemispheres and between the atmosphere over land and ocean, the NIES model shows efficient horizontal mixing and a smaller latitudinal gradient in $\mathrm{SF}_{6}$ compared to the other models and observations. We find consistent differences between models concerning vertical mixing of the tro-
\end{abstract}

posphere, expressed as AoA differences and modelled ${ }^{222} \mathrm{Rn}$ gradients between 950 and $500 \mathrm{hPa}$. All models agree, however, on an interesting asymmetry in inter-hemispheric mixing, with faster transport from the Northern Hemisphere surface to the Southern Hemisphere than vice versa. This is attributed to a rectifier effect caused by a stronger seasonal cycle in boundary layer venting over Northern Hemispheric land masses, and possibly to a related asymmetric position of the intertropical convergence zone. The calculated AoA in the mid-upper stratosphere varies considerably among the models (4-7 years). Finally, we find that the inter-model differences are generally larger than differences in AoA that result from using the same model with a different resolution or convective parameterisation. Taken together, the AoA model inter-comparison provides a useful addition to traditional approaches to evaluate transport timescales. Results highlight that inter-model differences associated with resolved transport (advection, reanalysis data, nudging) and parameterised transport (convection, boundary layer mixing) are still large and require further analysis. For this purpose, all model output and analysis software are available. 


\section{Introduction}

The composition of the atmosphere is determined by exchange processes at the Earth's surface, transport processes within the atmosphere, and chemical and physical conversion processes. For example, the atmospheric distribution of the $\mathrm{CH}_{4}$ mixing ratio is driven by natural and anthropogenic emissions at the Earth's surface, atmospheric transport, and removal that is primarily driven by the atmospheric oxidants $\mathrm{OH}, \mathrm{Cl}$, and $\mathrm{O}\left({ }^{1} \mathrm{D}\right)$ (Myhre et al., 2013). The estimated atmospheric lifetime of $\mathrm{CH}_{4}$ is approximately 9 years (Prather et al., 2012) mainly due to oxidation within the troposphere. Although some $\mathrm{CH}_{4}$ destruction occurs in the stratosphere (Boucher et al., 2009), as witnessed by the decaying mixing ratios with altitude, the slow atmospheric transport from the troposphere to the stratosphere limits its impact on the atmospheric lifetime of $\mathrm{CH}_{4}$. Other atmospheric constituents have widely different budgets. $\mathrm{SF}_{6}$, for instance, has purely anthropogenic sources, mostly in the Northern Hemisphere $(\mathrm{NH})$, and is only broken down in the upper stratosphere (Kovács et al., 2017), resulting in a very long atmospheric lifetime of more than 1000 years. In contrast, ${ }^{222} \mathrm{Rn}$ emanates naturally from land surfaces and quickly decays radioactively with a half-life of 3.8 days.

To better understand the changes in the atmosphere, general circulation models (GCMs) or chemistry transport models (CTMs) are used to simulate its composition. While CTMs use archived meteorological fields to calculate transport, GCMs calculate their own meteorology. To track the observed state of the atmosphere, the GCMs can be nudged towards meteorological reanalysis data (e.g. Law et al., 2008). Comparing results of these models to atmospheric observations allows the assessment of the model performance. Depending on the atmospheric compound, various aspects of atmospheric transport can be investigated. Jacob et al. (1997) used ${ }^{222} \mathrm{Rn}$ and other short-lived tracers to evaluate the convective and synoptic-scale transport in CTMs. Since the early 1990s, the atmospheric tracer transport model intercomparison project (TransCom) has carried out studies to quantify and diagnose the uncertainty in inversion calculations of the global carbon budget that result from errors in simulated atmospheric transport. Initially, TransCom focused on non-reactive tropospheric species such as $\mathrm{SF}_{6}$ (Denning et al., 1999) and $\mathrm{CO}_{2}$ (Law et al., 1996, 2008). A more recent TransCom model inter-comparison (Patra et al., 2011) focused on the ability of models to properly represent atmospheric transport of $\mathrm{CH}_{4}$, focussing on vertical gradients, its average long-term trends, seasonal cycles, inter-annual variations (IAVs) and inter-hemispheric (IH) gradients. The study concluded that models with faster IH exchange for $\mathrm{SF}_{6}$ have smaller IH gradients in $\mathrm{CH}_{4}$. The estimated IH exchange time, calculated based on a time-invariant $\mathrm{SF}_{6}$ emission rate, remained relatively constant over the period of the analysis (1996-2007). Interestingly, a recent study highlighted the importance of IH transport variations in explain- ing the $\mathrm{CO}_{2}$ mixing ratio difference between Mauna Loa in the NH and Cape Grim, Tasmania, in the Southern Hemisphere (SH) (Francey and Frederiksen, 2016). Specifically, the $0.8 \mathrm{ppm}$ step-like increase in this difference between 2009 and 2010 was attributed to the opening and closing of the upper-tropospheric equatorial westerly duct (Waugh and Funatsu, 2003), with an open-duct pattern from July 2008 to June 2009 (fast IH exchange), followed by closed-duct conditions from July 2009 to June 2010 (slow IH exchange). Confirming this mechanism, Pandey et al. (2017) also found faster $\mathrm{IH}$ transport of $\mathrm{CH}_{4}$ during the strong La Niña in 2011 using the TM5 CTM. The timescale of IH transport is an important parameter for atmospheric inversion studies. In these studies atmospheric observations are used to infer surface flux magnitude and distribution. For a long-lived greenhouse gas like $\mathrm{CH}_{4}$ fast $\mathrm{IH}$ transport implies that a larger fraction of the emissions will be attributed to the NH (Patra et al., 2014, 2011).

The efficiency of models to mix the planetary boundary and to vent emissions to the overlying free atmosphere has been studied using $\mathrm{SF}_{6}$ and has generally revealed too slow a mixing over midlatitude continents in the TM5 (Peters et al., 2004) and MOZART models (Gloor et al., 2007). Together with the convective parameterisation, this determines the rate by which emissions (e.g. $\mathrm{SF}_{6}$ and ${ }^{222} \mathrm{Rn}$ ) are mixed vertically and inter-hemispherically (Locatelli et al., 2015a).

Another transport timescale relevant for atmospheric composition studies is troposphere-stratosphere exchange (Holton et al., 1995), driven by the Brewer-Dobson circulation (Butchart, 2014). Depending on the greenhouse gas scenario, global climate model projections predict an acceleration of this global mass circulation of tropospheric air through the stratosphere. Stratospheric AoA and its temporal trend have been determined from $\mathrm{SF}_{6}$ measurements from the MIPAS satellite (Stiller et al., 2012) and from balloon observations (Engel et al., 2009). Using a suite of stratospheric observations, Fu et al. (2015) quantified the acceleration of the Brewer-Dobson circulation as $2.1 \%$ per decade for 1980-2009. Other modelling and experimental studies revealed that the atmospheric composition of the tropopause layer strongly depends on the mixing processes that occur on a wide range of spatiotemporal scales (Berthet et al., 2007; Hoor et al., 2010; Prather et al., 2011; Hsu and Prather, 2014).

Transport of trace gases in CTMs and GCMs is determined by several factors, for which various choices are possible. First, winds and the choice of advection scheme drive the large-scale dispersion and IH transport of tracers. While CTMs directly use winds from a meteorological reanalysis product, GCMs calculate their own meteorology and optionally apply a nudging scheme to simulate the transport of tracers (e.g. Law et al., 2008). Second, parameterised sub-gridscale processes such as boundary layer mixing and convection determine vertical gradients and the rate of IH transport (e.g. Locatelli et al., 2015a). Finally, other differences may be 
caused by the horizontal and vertical grid of the model and other issues related to spatial and temporal integration. For example, by doubling the vertical resolution of their GCM, Locatelli et al. (2015a) largely improved the representation of $\mathrm{SF}_{6}$ transport from the troposphere to the stratosphere. Similarly, Bândă et al. (2015) reported large differences in the stratospheric dispersion of the 1991 Pinatubo plume when increasing the vertical resolution in TM5 from 34 to $60 \mathrm{lev}$ els.

To investigate the impact of these choices on the participating models, this paper will present the first results of the TransCom AoA inter-comparison study. The concept of AoA originates from stratospheric studies (Hall and Prather, 1993; Hall and Plumb, 1994; Neu and Plumb, 1999; Hall et al., 1999). In brief, the age spectrum in the stratosphere $G\left(x, t \mid t_{0}\right)$ is calculated as a type of Green's function that propagates a tropospheric mixing ratio boundary condition into the stratosphere. Given a location $x$ in the stratosphere, $G \delta t$ represents the fraction of air at $x$ that was lost in the troposphere in the time interval between $t-t_{0}$ and $t-t_{0}+\delta t$ (Hall et al., 1999). In practical model applications focussing on stratospheric age spectra, $G\left(x, t \mid t_{0}\right)$ is calculated as the response of a time-dependent boundary condition $\delta\left(t-t_{0}\right)$ specified in a forcing volume in the troposphere. More recently, this concept has also been applied to tropospheric studies (Holzer and Hall, 2000; Waugh et al., 2013; Holzer and Waugh, 2015). In this AoA inter-comparison, we will only analyse the mean AoA. In the terminology of Holzer and Hall (2000), AoA is defined as the mean transit time, with the age spectrum being the transit-time probability density function. This property can be easily extracted from model simulations of a passive tracer with linearly growing boundary conditions in a specified atmospheric volume. We will outline the inter-comparison protocol in Sect. 2. The resulting model output focussing on the simulation period 2000-2010 is compared in Sect. 3 and discussed in Sect. 4. Finally, the main conclusions are summarised in Sect. 5.

\section{Method}

\subsection{AoA protocol}

In order to compare transport timescales of a suite of CTMs and GCMs, a protocol was developed that allows a straightforward implementation in existing atmospheric models. We defined five AoA tracers (Table 1) for which linearly growing boundary conditions are applied. These AoA tracers are chosen to study IH transport, transport to the stratosphere, and air mass transport between land and ocean. The mixing ratios of these tracers in the models are initialised to zero on 1 January 1988 and simulations are run to the end of 2014.

According to the protocol, the mixing ratio of each AoA tracer in its respective forcing volume is set every time step to a value $B=f \times t$, with $t$ the elapsed time (in
Table 1. The five AoA tracers and their forcing volume.

\begin{tabular}{ll}
\hline AoA tracer & Forcing volume \\
\hline Surface & Surface $<100 \mathrm{~m}$ \\
NHsurface & NH surface $<100 \mathrm{~m}$ \\
SHsurface & SH surface $<100 \mathrm{~m}$ \\
Land & Land $<100 \mathrm{~m}$ \\
Ocean & Ocean $<100 \mathrm{~m}$ \\
\hline
\end{tabular}

s) since January 1988 and $f$ a forcing constant of $1 \times$ $10^{-15} \mathrm{~mol} \mathrm{~mol}^{-1} \mathrm{~s}^{-1}$. As a result, the mixing ratio in the forcing volume will have a value of $852.0768 \mathrm{nmol} \mathrm{mol}^{-1}$ at the end of the simulation and lower values elsewhere. In theory, numerical issues with advection might lead to small wiggles in the vicinity of strong mixing ratio gradients. This may result in small unphysical negative mixing ratios that cannot be handled by some model transport schemes. To remedy this, models may be initialised with a uniform $100 \mathrm{nmol} \mathrm{mol}^{-1}$ initial condition, a value that is subtracted before further analysis.

Modellers are requested to calculate the exact fraction of each grid box within the forcing volume. This calculation involves the land mask, the fraction of the grid box in either the $\mathrm{NH}$ and $\mathrm{SH}$, and the geopotential height. The protocol provides example code to help with the implementation. Importantly, the mixing ratio of the grid boxes within the forcing volume was set according to

$X_{\text {new }}=f_{\text {set }} \times B+\left(1-f_{\text {set }}\right) \times X_{\text {old }}$,

where $f_{\text {set }}$ is the fraction of the grid box within the forcing volume and $X_{\text {old }}$ the mixing ratio before the forcing procedure. Note that in locations where $f_{\text {set }}=0$, nothing needs to be changed, and the mixing ratio changes are purely driven by transport from the forcing volume. To diagnose AoA, the simulated mixing ratios $X$ in the atmosphere can be converted into AoA by $L=t-\frac{X}{f}$, with $L$ the AoA in seconds and $t$ the elapsed time of the simulation.

Figure 1 shows the simulated mixing ratios and applied forcing for the tracer "Surface" at the location of the Cabauw tower from 6 to 15 May 2010, together with the derived AoA. We use here output from the TM5 model on $1 \times 1^{\circ}$ resolution (see Table 4). At $20 \mathrm{~m}$ above the surface during the nighttime, AoA is generally close to zero, due to the fact that the volume is forced in the lowest $100 \mathrm{~m}$, and vertical mixing is limited in a stable nocturnal boundary layer. During the daytime, however, older air from aloft is mixed in, and the AoA increases depending on the depth of the mixing layer and the strength of the vertical mixing. At $200 \mathrm{~m}$, outside the forcing volume, air is generally older. During some nights, e.g. from 8 to 9 May, the surface becomes decoupled from the air masses aloft, signalling a stable boundary layer. Note that the depth of the lowest model layer is approximately $20 \mathrm{~m}$, which implies that this layer is entirely within the forcing 

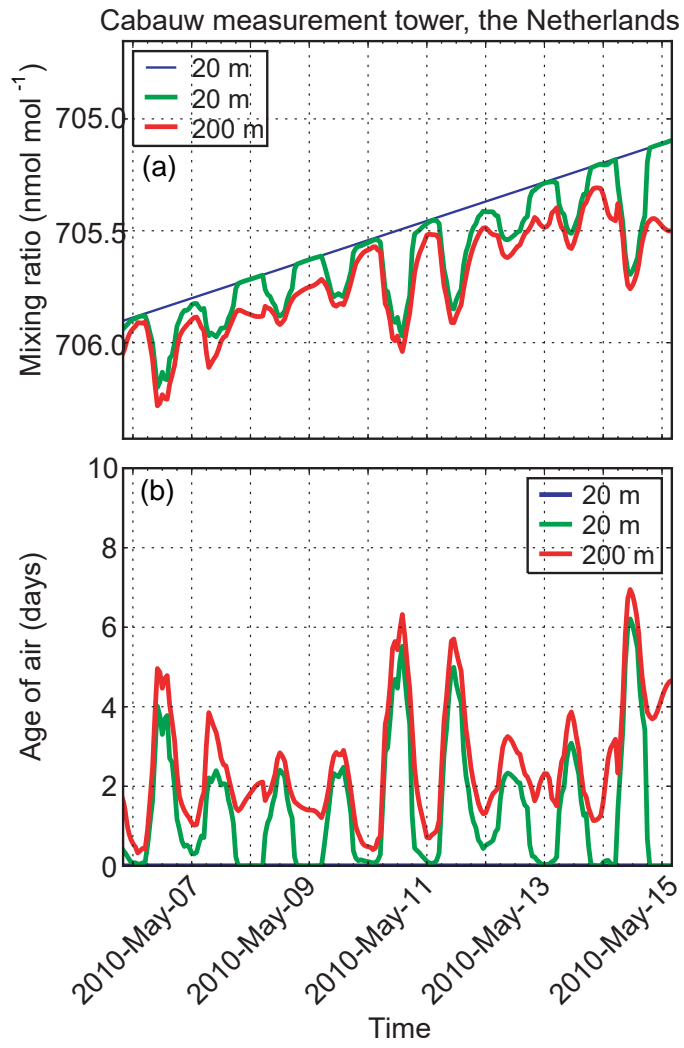

Figure 1. (a) Mixing ratios of an AoA tracer simulated by the TM5 model (TM5_1x1) forced at the surface along the Cabauw measurement tower in the Netherlands during May 2010. The blue line represents the applied forcing. (b) Similar, but transferred to AoA.

volume (the applied forcing is indicated by the blue line). However, TM5 still calculates a non-zero AoA in the lowest model layer because the mixing ratios are sampled after vertical transport, which mixes in older air (Krol et al., 2005). We do not provide recommendations on the sampling strategy. For instance, models that sample right after forcing, simulate a linear mixing ratio increase at $20 \mathrm{~m}$ (blue line in Fig. 1a) and a constant and zero AoA at $20 \mathrm{~m}$ (blue line in Fig. 1b). The current paper will focus on large-scale transport timescales, and we found no major influence of this sampling strategy on the results.

To complement the AoA tracers, modellers were also requested to simulate the tracers listed in Table 2. Simulations of ${ }^{222} \mathrm{Rn}$ are intended to study vertical and synopticscale transport (Jacob et al., 1997); $\mathrm{SF}_{6}$ is used to diagnose IH transport, stratosphere-troposphere exchange, and stratospheric AoA; E90 is used to diagnose the "chemical" tropopause and will be compared to Prather et al. (2011). Note that we also included a ${ }^{222} \mathrm{Rn}$ simulation with monthly varying emissions over Europe during 2006-2010, based on the high-resolution emission maps presented in Karstens et al. (2015). The current paper will, however, not analyse these simulations.
Homogeneous surface emissions (in $\mathrm{kg} \mathrm{m}^{-2} \mathrm{~s}^{-1}$ ) of E90 $\left(E_{\mathrm{E} 90}\right)$ are calculated such that the mean steady-state atmospheric mixing ratio of E90 will approach $100 \mathrm{nmol} \mathrm{mol}^{-1}$ :

$E_{\mathrm{E} 90}=\frac{M_{\mathrm{atm}} \times 100 \times 10^{-9}}{\tau_{\mathrm{E} 90} \times 4 \pi r^{2}}$,

with $M_{\text {atm }}$ the atmospheric mass $(\mathrm{kg}), r$ the radius of the Earth $(\mathrm{m})$, and $\tau_{\mathrm{E} 90}$ the e-folding lifetime (90 days in units s) of E90.

Emissions of $\mathrm{SF}_{6}$ based on EDGAR4.0 (Emission Database for Global Atmospheric Research) with corrections suggested by Levin et al. (2010) are given in Table 3. The emission distribution is similar to Patra et al. (2011).

NetCDF-formatted input files were provided with emissions on $1^{\circ} \times 1^{\circ}$ resolution and initial $\mathrm{SF}_{6}$ mixing ratios for 1 January 1988. In terms of output, modellers were requested to provide monthly mean 3-D mixing ratios and hourly mixing ratio time series at 247 atmospheric measurement stations (interpolated or grid value). Furthermore, hourly atmospheric profiles of mixing ratios and meteorological variables ( $u$ wind, $v$ wind, surface pressure, boundary layer height, geopotential height) were requested at 119 locations. In this first analysis, we will concentrate on the output of monthly mean mixing ratios that have been provided by three CTMs and three GCMs, some of them running in different configurations. Table 4 lists the participating models along with their horizontal and vertical resolution. Three models (LMDZ, EMAC, ACTM) run in "online" mode, meaning that meteorology is calculated by the physics module of the model and nudged towards a reanalysis dataset, such as ERA-Interim (Dee et al., 2011), provided by the European Centre for Medium-Range Weather Forecasts and JRA-25 from the Japanese Meteorological Agency (Onogi et al., 2007; Chiaki and Toshiki, 1016). Three other models (TM5, NIES, TOMCAT) run in "offline" mode, and directly read in meteorological driver data from a reanalysis. TM5_EC-Earth reads in meteorological data from the ECEarth model (Hazeleger et al., 2010) that is nudged to ERAInterim (see Sect. 2.3)

In the next subsections, specific information on the participating models and the measurements is given.

\subsection{LMDZ}

LMDZ, developed at Laboratoire de Météorologie Dynamique with " $Z$ " standing for zoom capacity, is the global general circulation model of the IPSL Earth system model (Hourdin et al., 2006, 2012). Here, we include two offline versions of LMDZ - LMDZ3 and LMDZ5A -, both with a horizontal resolution of $1.875^{\circ}$ (latitude) $\times 3.75^{\circ}$ (longitude) and a vertical resolution of 39 hybrid sigma-pressure levels, commonly chosen for global inverse studies using LMDZ (Chevallier, 2015; Locatelli et al., 2015b; Yin et al., 2017). These two versions are different in terms of the physical parameterisation of deep convection and boundary layer mix- 
Table 2. Additional tracers in the model inter-comparison.

\begin{tabular}{ll}
\hline Tracer & Remarks \\
\hline${ }^{222} \mathrm{Rn}$ & Radon tracer, similar to Jacob et al. (1997), Law et al. (2008), Patra et al. (2011) \\
${ }^{222} \mathrm{RnE}$ & $\mathrm{As}^{222} \mathrm{Rn}$, but with specific monthly emissions over Europe in 2006-2010 (Karstens et al., 2015) \\
$\mathrm{SF}_{6}$ & $\mathrm{SF}_{6}$ tracer, similar to Patra et al. (2011), but with updated yearly emissions (Table 3) \\
$\mathrm{E} 90$ & Tracer with surface emissions and atmospheric lifetime of 90 days (Prather et al., 2011) \\
\hline
\end{tabular}

Table 3. Yearly emissions of $\mathrm{SF}_{6}$ for the period 1988-2015.

\begin{tabular}{rrrr}
\hline Year & $\begin{array}{r}\text { Source } \\
\left(\mathrm{mmol} \mathrm{s}^{-1}\right)\end{array}$ & Year & $\begin{array}{r}\text { Source } \\
\left(\mathrm{mmol} \mathrm{s}^{-1}\right)\end{array}$ \\
\hline 1988 & 934 & 2002 & 1223 \\
1989 & 938 & 2003 & 1258 \\
1990 & 1036 & 2004 & 1268 \\
1991 & 1116 & 2005 & 1299 \\
1992 & 1210 & 2006 & 1366 \\
1993 & 1303 & 2007 & 1475 \\
1994 & 1381 & 2008 & 1555 \\
1995 & 1392 & 2009 & 1577 \\
1996 & 1312 & 2010 & 1599 \\
1997 & 1208 & 2011 & 1642 \\
1998 & 1162 & 2012 & 1685 \\
1999 & 1177 & 2013 & 1729 \\
2000 & 1201 & 2014 & 1772 \\
2001 & 1197 & 2015 & 1816 \\
\hline
\end{tabular}

ing. LMDZ3 uses the deep convection scheme of Tiedtke (1989) and the boundary layer mixing scheme of Louis (1979). LMDZ5A is an updated version that uses the deep convection scheme of Emanuel (1991) and the boundary layer mixing parameterisation from Louis (1979), further adjusted according to Deardorff (1966). More details regarding the configurations of the physics and comparison to other versions are described in Locatelli et al. (2015a). Sea surface temperature and sea ice coverage from ERA-Interim are used as boundary conditions. Horizontal winds are nudged towards ERA-Interim wind fields with a relaxation time of $3 \mathrm{~h}$.

\subsection{TM5}

The TM5 model (Krol et al., 2005) has different application areas with a common core. TM5 allows for a flexible grid definition with two-way nested zoom regions. This version is mainly used in inverse modelling applications, focussing on $\mathrm{CO}_{2}$ (Peters et al., 2010), $\mathrm{CH}_{4}$ (Bergamaschi et al., 2013; Houweling et al., 2014), and CO (Krol et al., 2013). The chemistry version of TM5 (Huijnen et al., 2010) was recently adapted for massive parallel computing (Williams et al., 2017). The AoA simulations were conducted in this so-called TM5-MP version.
The TM5 model is used in three versions that differ in horizontal resolution and in the way meteorological data are used. The version named TM5_3 2 simulated the AoA experiment at a resolution of $3^{\circ} \times 2^{\circ}$ (longitude $\times$ latitude). In the version TM5_1x1, a horizontal resolution of $1^{\circ} \times 1^{\circ}$ was used. TM5_1x1 and TM5_3x2 refer to simulations with the offline TM5-MP version that reads in the meteorological fields from files. Like earlier model versions, TM5_1x1 and TM5_3 2 are driven by ERA-Interim and updated every $3 \mathrm{~h}$, with time interpolation during time integration. For this inter-comparison, we include all 60 vertical levels provided by the ECMWF ERA-Interim reanalysis. Convective mass fluxes are derived from entrainment and detrainment rates from the ERA-Interim dataset. This replaces the convective parameterisation used in the previous TransCom intercomparison (Patra et al., 2011), which was based on Tiedtke (1989). According to Tsuruta et al. (2017) the mass fluxes produced with the ERA-Interim dataset lead to faster interhemispheric transport compared to the old model version using the Tiedtke (1989) scheme that was used in the earlier TransCom study (Patra et al., 2011).

The vertical diffusion in the free troposphere is calculated according to Louis (1979) and in the boundary layer by the approach of Holtslag and Boville (1993). Diurnal variability in the boundary layer height is determined using the parameterisation of Vogelezang and Holtslag (1996). Advective fluxes are calculated using the slopes scheme (Russel and Lerner, 1981), with a refinement in time step whenever the Courant-Friedrichs-Lewy (CFL) criterion is violated.

TM5_EC-Earth is the atmospheric transport model of the earth system model EC-Earth version 3.2.2 (Version 2.3 is described in Hazeleger et al., 2010, 2012) The main differences between the two versions are an increased resolution (from T159 with 62 vertical layers in version 2.3 to T255 with 91 vertical layers in version 3.2.2) and updated versions of the separate model components. Only the atmospheric components are used in this study. The dynamical core of EC-Earth is based on the Integrated Forecasting System (IFS), version cy36r4 (Molteni et al., 2011). In contrast to the offline versions of TM5, the dynamical properties of the atmosphere are simulated by EC-Earth in TM5_ECEarth. EC-Earth was nudged towards ERA-Interim data for temperature, vorticity, divergence, and the logarithm of the surface pressure. The nudging used a relaxation time of $6 \mathrm{~h}$, allowing for continuous atmospheric dynamics when follow- 
Table 4. Short-hand notation of the models participating in this study, along with model information.

\begin{tabular}{llrll}
\hline Model submission & Base model & Longitude $\times$ latitude & Vertical levels & Meteorological driver data \\
\hline LMDZ3 & LMDZ & $3.75^{\circ} \times 1.875^{\circ}$ & 39 hybrid $\sigma$-pressure & Nudged to ERA-Interim \\
LMDZ5A & LMDZ & $3.75^{\circ} \times 1.875^{\circ}$ & 39 hybrid $\sigma$-pressure & Nudged to ERA-Interim \\
TM5_3x2 & TM5 & $3^{\circ} \times 2^{\circ}$ & 60 hybrid $\sigma$-pressure & ERA-Interim \\
TM5_1x1 & TM5 & $1^{\circ} \times 1^{\circ}$ & 60 hybrid $\sigma$-pressure & ERA-Interim \\
TM5_EC-Earth & TM5 & $3^{\circ} \times 2^{\circ}$ & 34 hybrid $\sigma$-pressure & EC-Earth, nudged to ERA-Interim \\
EMAC_T63 & EMAC & $\approx 1.875^{\circ} \times 1.875^{\circ}$ & 90 hybrid $\sigma$-pressure & Nudged to ERA-Interim \\
EMAC_T106 & EMAC & $\approx 1.125^{\circ} \times 1.125^{\circ}$ & 90 hybrid $\sigma$-pressure & Nudged to ERA-Interim \\
ACTM & ACTM & $\approx 2.81^{\circ} \times 2.81^{\circ}$ & $67 * \sigma$ up to 90 km & Nudged to JRA-25 \\
NIES & NIES & $2.5^{\circ} \times 2.5^{\circ}$ & 32 hybrid $\sigma-\theta$ up to 5 hPa & JRA-25 \\
TOMCAT & TOMCAT & $\approx 2.81^{\circ} \times 2.81^{\circ}$ & 60 hybrid $\sigma$-pressure & ERA-Interim \\
\hline
\end{tabular}

* Only the lower 50 layers have been submitted.

ing the ERA-Interim data. Every $6 \mathrm{~h}$, the meteorological data are transferred via de OASIS3 coupler (Valcke, 2013) to TM5-MP, which uses these data to calculate the actual atmospheric transport as described above. Apart from the meteorological data, the model code of TM5-EC-Earth is similar to TM5_3 2 , but with a reduced number of vertical levels (34, i.e. a subset of the 91 levels used in IFS, instead of 60).

\subsection{EMAC}

The EMAC (ECHAM/MESSy Atmospheric Chemistry) model employed in this study, combines an updated version 2.50 of the MESSy (Modular Earth Submodel System) framework (Jöckel et al., 2005, 2010) with version 5.3.02 of the ECHAM5 (European Centre Hamburg) general circulation model (Roeckner et al., 2006). The version of the EMAC model used here, first described by Jöckel et al. (2006), incorporates a recent update to convective transport of tracers (Ouwersloot et al., 2015) and is further improved upon to facilitate the nudging of AoA tracers. These modifications are included in version 2.52 of MESSy.

Dynamical properties are simulated by EMAC itself. The model dynamics are weakly nudged in the spectral space, nudging temperature, vorticity, divergence, and surface pressure (Jeuken et al., 1996). Different nudging coefficients are used for different vertical levels, with no nudging in the boundary layer and above $\sim 10 \mathrm{hPa}$ and with maximum nudging in the free troposphere. Convective mass fluxes are diagnosed in the CONVECT submodel (Tost et al., 2006), while the resulting transport is calculated by the CVTRANS model (Tost et al., 2010; Ouwersloot et al., 2015). The simulations with EMAC make use of 90 vertical hybrid sigmapressure levels. Data are available for two horizontal resolutions: T63 $(192 \times 96$ grid $)$ with a fixed time step of $6 \mathrm{~min}$ and T106 $(320 \times 160$ grid $)$ with a fixed time step of $4 \mathrm{~min}$.

\subsection{ACTM}

The CCSR/NIES/FRCGC (Center for Climate System Research/National Institute for Environmental Studies/Frontier Research Center for Global Change) atmospheric general circulation model (AGCM)-based chemistry transport model (ACTM) has been developed for simulations of long-lived gases in the atmosphere (Numaguti et al., 1997; Patra et al., 2009a, 2014). The ACTM simulations are performed at a horizontal resolution of T42 spectral truncation $(\sim 2.8 \times$ $2.8^{\circ}$ ) with $67 \sigma$ levels in the vertical and model top at $\sim$ $90 \mathrm{~km}$. The horizontal winds and temperature of ACTM are nudged with JRA-25. The nudging forces the AGCM-derived meteorology towards the reanalysed horizontal winds $(u$ and $v$ components) and temperature $(T)$ with relaxation times of 2 and 5 days, respectively, except for the top and bottom model layers.

The heat and moisture exchange fluxes at the Earth's surface are calculated using inter-annually varying monthlymean sea ice and sea surface temperature from the Hadley Centre observational data products (Rayner et al., 2003). Tracer advection is performed using a fourth-order flux-form advection scheme comprising of the monotonic piecewise parabolic method (Colella and Woodward, 1984) and a fluxform semi-Lagrangian scheme (Lin and Rood, 1996).

Sub-grid-scale vertical fluxes are approximated using a non-local closure scheme based on Holtslag and Boville (1993) and the level 2 scheme of Mellor and Yamada (1974). The cumulus parameterisation scheme is simplified from Arakawa and Schubert (1974) and used for calculating the updraft and downdraft of tracers by cumulus convection.

\subsection{NIES}

The NIES Eulerian three-dimensional offline transport model is driven by the JRA-25 dataset. It employs a reduced horizontal latitude-longitude grid with a spatial resolution of $2.5^{\circ} \times 2.5^{\circ}$ near the equator (Maksyutov and Inoue, 1999) and a flexible hybrid sigma-isentropic $(\sigma-\theta)$ vertical coordi- 
Table 5. Availability of source code for the models featured in this paper.

\begin{tabular}{|c|c|}
\hline Short name & Code availability \\
\hline LMDZ & $\begin{array}{l}\text { LMDZ is open-source free software under licence CeCILL (http://www.cecill.info/licences/Licence_CeCILL_ } \\
\text { V2-en.html, last access: } 6 \text { July 2017). The versions used here are available online via http://svn.lmd.jussieu.fr/ } \\
\text { LMDZ (last access: } 6 \text { July 2017). }\end{array}$ \\
\hline TM5 & $\begin{array}{l}\text { TM5 version control is performed on the SVN server of the Dutch Met Office (KNMI). The AoA simulations are } \\
\text { performed using TM5-MP, revision r182, committed on } 29 \text { May 2017. Access to the SVN server is granted to } \\
\text { researchers actively participating in model development. }\end{array}$ \\
\hline TM5_EC-Earth & $\begin{array}{l}\text { TM5_EC-Earth is the TM5-MP version incorporated in EC-Earth version 3.2.2. Information about the model and } \\
\text { access to the code are available at http://www.ec-earth.org (last access: } 6 \text { July 2017). The specific version used } \\
\text { for this study can be found under the branch r4353-Age_of-Air. This version consists of the main developmental } \\
\text { version of EC-Earth updated until } 4 \text { July 2017, supplemented with the AoA code of TM5. }\end{array}$ \\
\hline EMAC & $\begin{array}{l}\text { The ECHAM/MESSy Atmospheric Chemistry (EMAC) model is a configuration of MESSy, which is being con- } \\
\text { tinuously further developed and applied by a consortium of institutions. The usage of MESSy and access to the } \\
\text { source code is licensed to all affiliates of institutions that are members of the MESSy Consortium. Institutions can } \\
\text { be a member of the MESSy Consortium by signing the Memorandum of Understanding. More information can be } \\
\text { found on the MESSy Consortium website (http://www.messy-interface.org, last access: } 6 \text { July 2017). }\end{array}$ \\
\hline ACTM & $\begin{array}{l}\text { The ACTM code is not open source. The model code is based on CCSR/NIES/FRCGC AGCM5.7b. The copyright } \\
\text { belongs to the developers at CCSR (Univ. Tokyo), NIES, and FRCGC (JAMSTEC). }\end{array}$ \\
\hline NIES & The NIES source code is proprietary. The model copyright is owned by developers at NIES. \\
\hline TOMCAT & $\begin{array}{l}\text { The TOMCAT code is not open source. The model is available to all UK researchers funded by the Natural Envi- } \\
\text { ronment Research Council (NERC) and other UK research councils. The model is also available to other scientists } \\
\text { with an interest in active collaboration with existing users, subject to limitations of resources to support the collab- } \\
\text { orations. }\end{array}$ \\
\hline
\end{tabular}

nate, which includes 32 levels from the surface up to $5 \mathrm{hPa}$ (Belikov et al., 2013b). The vertical transport for all levels above the tropopause and higher than a potential temperature level of $295 \mathrm{~K}$ follows a climatological adiabatic heating rate. The parameterisation of turbulent diffusivity separates transport processes in the planetary boundary layer (provided by the ECMWF ERA-Interim reanalysis) from the free troposphere following the approach by Hack et al. (1993). Vertical mass fluxes due to cumulus convection are based on the convective precipitation rate provided by the reanalysis dataset (Austin and Houze Jr., 1973; Belikov et al., 2013a). A modified Kuo-type parameterisation scheme (Grell et al., 1994) is used to set cloud top and cloud bottom height. Transport by convective updrafts and downdrafts includes entrainment and detrainment processes as described by Tiedtke (1989).

\subsection{TOMCAT}

TOMCAT/SLIMCAT is a global 3-D offline chemical transport model (Chipperfield, 2006). It is used to study a range of chemistry-aerosol-transport issues in the troposphere (e.g. Monks et al., 2017) and stratosphere (e.g. Chipperfield et al., 2015). The model is usually forced by ERA-Interim, although GCM output can also be used. When using ECMWF fields, as in the experiments described here, the model reads in the 6-hourly fields of temperature, humidity, vorticity, divergence, and surface pressure. The resolved vertical motion is calculated online from the vorticity. The model has different options for the parameterisations of sub-grid-scale tracer transport by convection (Stockwell and Chipperfield, 1999; Feng et al., 2011) and boundary layer mixing (Louis, 1979; Holtslag and Boville, 1993). Tracer advection is performed using the conservation of the second-order moment scheme of Prather et al. (1987). For the experiments the model was run at a horizontal resolution of $2.8^{\circ} \times 2.8^{\circ}$ with 60 hybrid $\sigma$-pressure levels from the surface to $\sim 60 \mathrm{~km}$. These follow the vertical levels from the meteorological fields from ERAInterim, which are used to force the model. Convective mass fluxes were diagnosed online using a version of the Tiedtke scheme (Stockwell and Chipperfield, 1999) and mixing in the boundary layer is based on the local scheme of Louis (1979). Previous work with the model has shown that these schemes tend to underestimate the mixing out of the boundary layer and convective transport to the upper troposphere (e.g. Feng et al., 2011), but these were the options available for the multi-decadal runs analysed here.

\subsection{Measurement data}

We will compare model results to latitudinal $\mathrm{SF}_{6}$ gradients measured by the National Oceanic \& Atmospheric Administration Earth System Research Laboratory (NOAA/ESRL) (Hall et al., 2011). We use the combined dataset constructed from flask data measured by the Halocarbons and other Atmospheric Trace Species (HATS) group and hourly Chromatograph for Atmospheric Trace Species (CATS) data (downloaded from https://www.esrl.noaa.gov/gmd/hats/ combined/SF6.html, last access: 6 July 2017) and include 


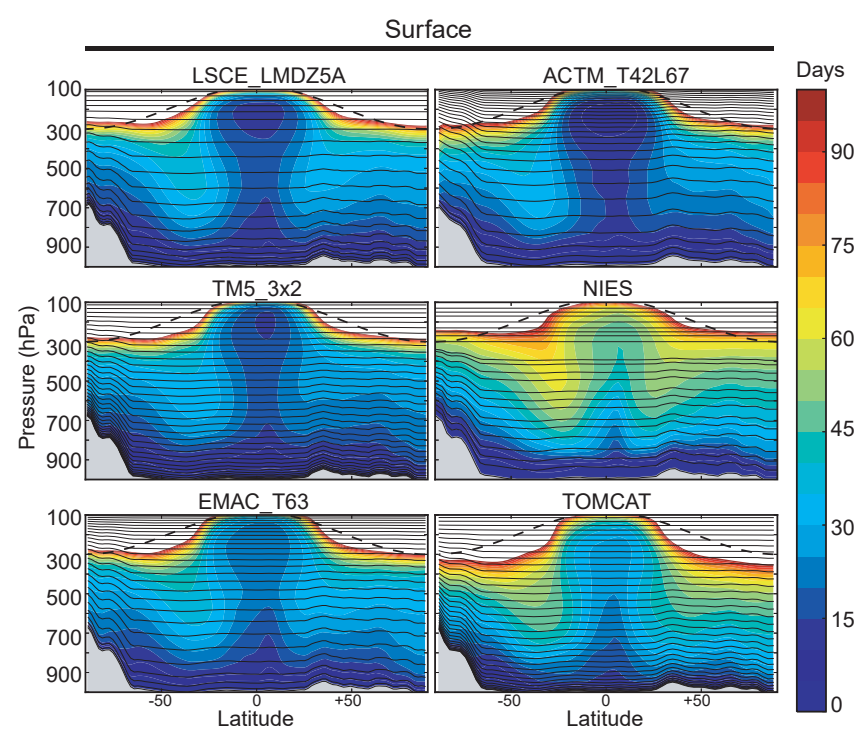

Figure 2. Zonally averaged AoA (days) in the troposphere for the tracer "Surface". The results have been averaged over the period 2000-2010 (11 years). The light grey areas correspond to the zonal mean orography in the models. The thin black lines denote the midpressure levels of the models. For reference, the dotted black line in all panels denotes the climatological tropopause (Lawrence et al., 2001). The white areas correspond to areas in which the air is older than 100 days.

only stations with a full measurement record in the period 2000-2011. To account for model-data offsets, 11-year time series with monthly resolution were constructed of the stations' mixing ratios with respect to the South Pole. The mean and standard deviations of these time series are added to the modelled latitudinal gradients below.

In Appendix A we further compare the simulated $\mathrm{SF}_{6}$ latitudinal and vertical gradients to measurements made during the High-performance Instrumented Airborne Platform for Environmental Research (HIAPER) Pole-to-Pole Observation (HIPPO) campaigns (Wofsy et al., 2011), similar to comparisons presented in Patra et al. (2014).

\section{Results}

\subsection{Tropospheric AoA}

First, we focus on zonal and multi-year averages to investigate differences among the models in IH and vertical transport in the troposphere. We created these averages by (i) averaging the monthly mean mixing ratios of the participating models zonally and over time and (ii) converting the mean mixing ratios to AoA. These latitude-pressure cross sections are presented in Fig. 2 for the AoA tracer Surface and in Fig. 3 for the AoA tracers "NHsurface" and "SHsurface" (see Table 1).
The AoA in the troposphere derived from the tracer Surface is generally younger than 100 days (Fig. 2). The 100day contour sharply marks the transition to the stratosphere at around $300 \mathrm{hPa}$ at the poles. In the tropics this transition is located at a pressure lower than $100 \mathrm{hPa}$, which generally agrees with the definition of the climatological tropopause given by Lawrence et al. (2001). Deep convective transport drives the vertical transport in the tropics, and this deep convective region is bounded by tongues of older air, signalling intrusions of stratospheric air (Holton et al., 1995). Although all models agree on this general pattern, clear differences are also present. Deep convective mixing in the tropics is strongest in ACTM, while TOMCAT and NIES generally show slower vertical transport and larger AoA gradients between the surface and the upper troposphere.

The tracers NHsurface (Fig. 3a) and SHsurface (Fig. 3b) are used to diagnose IH transport. Generally, the air at high latitudes has an age of between 0.6 and 1.2 years in the hemisphere opposite to the forcing volume. Here, all models agree on an interesting asymmetry: AoA derived from SHsurface around the North Pole is $0.10-0.17$ years older than AoA derived from NHsurface around the South Pole. TOMCAT, diagnosed with slow vertical mixing, has older air at high latitudes, while NIES (also slow vertical mixing) has highlatitude ages more in line with other models, indicating fast horizontal transport near the surface. Figure 3 illustrates the fact that the exchange of air between the hemispheres proceeds faster at higher altitudes $(200-500 \mathrm{hPa})$ (Prather et al., 1987), and consequently steep AoA gradients are observed close to the surface in the tropics.

\subsection{AoA derived from the "Land" and "Ocean" tracers}

Figure 4 shows AoA derived from the tracers Land (panel a) and Ocean (panel b) evaluated at the lowest model level. Oldest air related to last contact with land is found over the Southern Ocean, with ages older than 100 days. Models generally agree on the fact that old air is found in the stationary high-pressure areas over the ocean that are related to the Hadley and Walker circulations. This agrees qualitatively with previous findings using the E90 tracer (Prather et al., 2011). The TOMCAT model, in the configuration used here, has systematically larger AoA at the surface. Dominant landocean transport patterns are easily discerned from the simulations with the Land tracer. Young air over oceans is found south-east of South America, north-west of Australia, and towards the north-east of North America and Asia, associated with the position of the upper-air jet stream. The oldest air in the southern east Pacific for the tracer Land indicates that this region is most isolated from the $\mathrm{NH}$ emissions. In accordance with this, the lowest $\mathrm{CH}_{4}$ mixing ratios on the Earth's surface are found at the NOAA site Easter Island (EIC). Patra et al. (2009b) attributed these to "old" air in combination with the strong removal of $\mathrm{CH}_{4}$ by $\mathrm{OH}$ at tropical latitudes. 
(a) $\mathrm{NH}$ surface
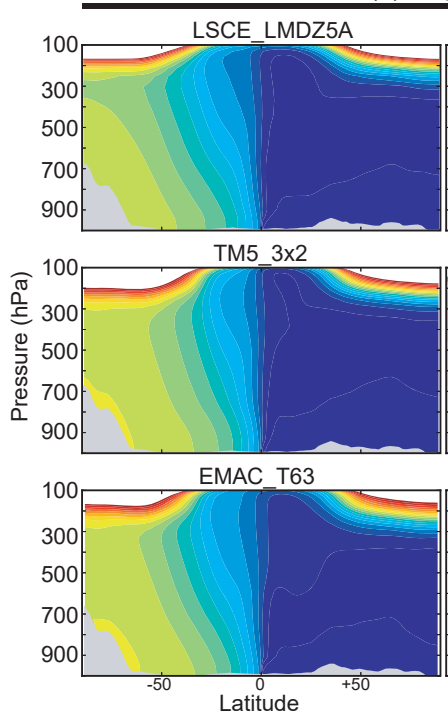

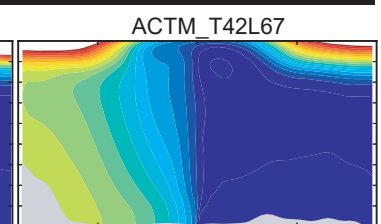

NIES

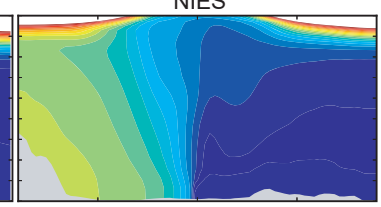

TOMCAT

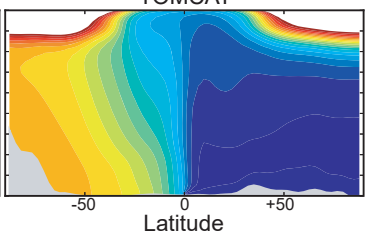

(b) $\mathrm{SH}$ surface
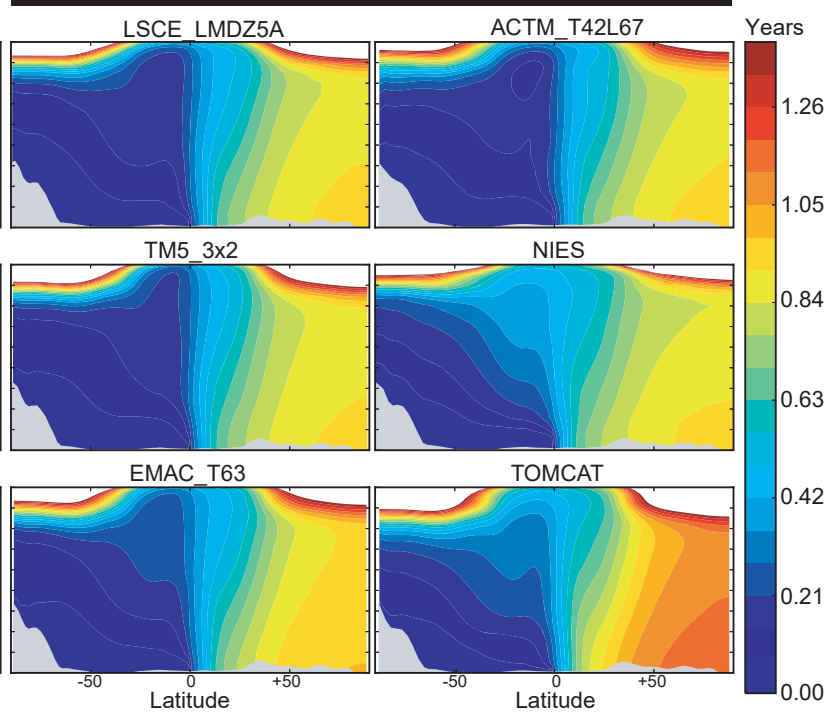

0.42

Figure 3. Zonally averaged AoA (years) in the troposphere for the tracers "NHsurface" (a) and "SHsurface" (b). The results have been averaged over the period 2000-2010 (11 years). The light grey areas correspond to the zonal mean orography in the models. The white areas correspond to regions in which the air is older than 1.4 years.

(a) Land

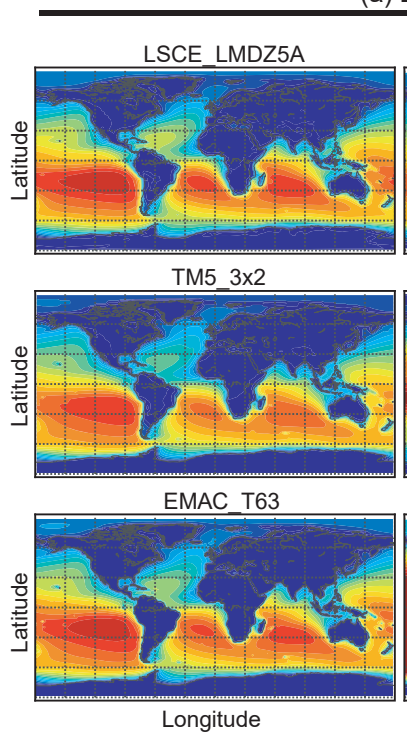

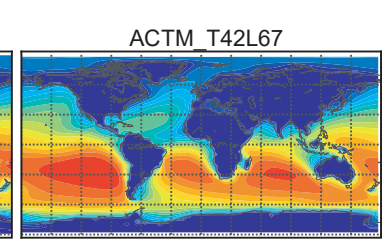

NIES

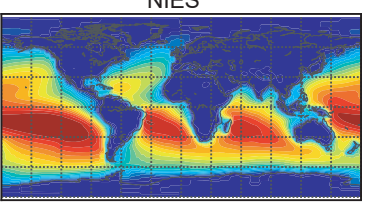

TOMCAT

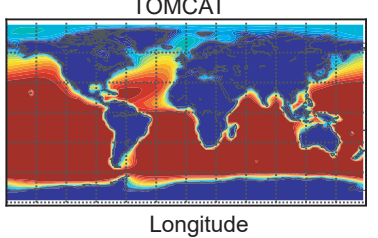

(b) Ocean

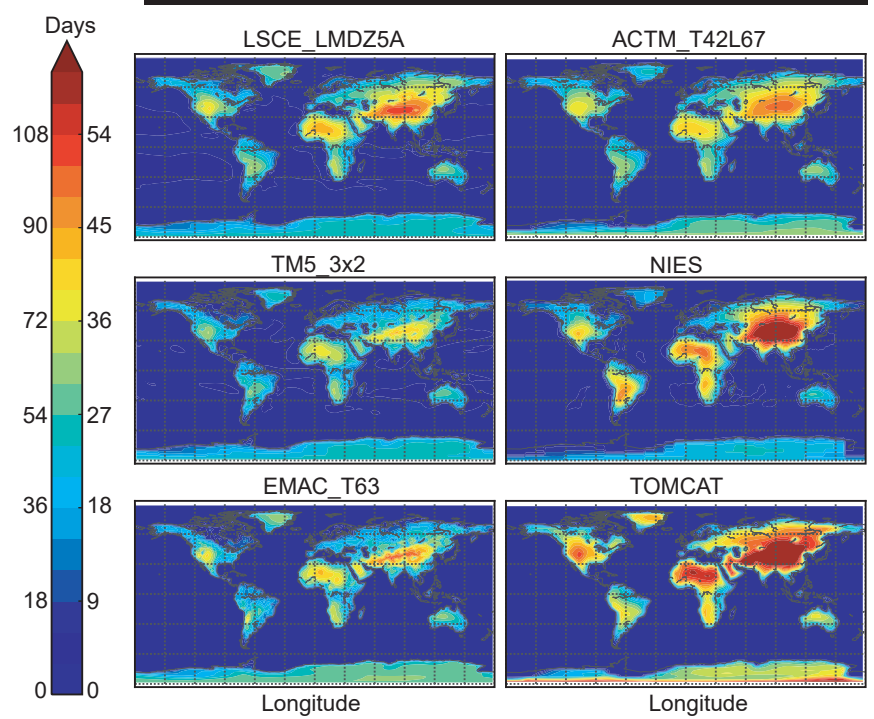

Figure 4. Latitude-longitude plot of the AoA (days) derived from the tracers "Land" (a) and "Ocean" (b), evaluated in the lowest model layer. The results have been averaged over the period 2000-2010 (11 years). Ages older than 120 days (land tracer) or 60 days (ocean tracer) appear in dark red.

The AoA derived from the tracer Ocean (Fig. 4b) generally shows ages less than 60 days over land, with the older ages logically located in deep inland areas. Its AoA over land is strongly determined by dominant circulation patterns such as the monsoon, trade winds, and jet streams. Although these patterns are similar in all models, the spread is considerable, with TOMCAT again showing the oldest air and TM5 showing the youngest air over land surfaces. These differences are related to the boundary layer parameterisations in the models and in the case of TOMCAT the use of the simple local Louis (1979) scheme. Earlier studies (Wang et al., 1999; Chipperfield, 2006) revealed that this type of local boundary layer (BL) mixing scheme leads to a slower exchange between the $\mathrm{BL}$ and the free atmosphere. 


\subsection{Stratospheric AoA}

We use the tracer Surface to compare the simulated stratospheric AoA. Here, it should be noted that differences in tropospheric mixing influence the results. For instance, the TOMCAT and NIES AoA are systematically older at the tropopause (see Fig. 2). Figure 5 shows the stratospheric AoA for all models from $100 \mathrm{hPa}$ to the top of the atmosphere, averaged over the period 2000-2010 (11 years). As expected, the oldest AoA is found at the high-altitude poles. Considerable model spread is found with the oldest air (up to 7 years) in LMDZ5A and the youngest air in ACTM ( $<5$ years). The transport in EMAC, TOMCAT, LMDZ, and TM5 is driven by - or nudged to - ERA-Interim meteorology (see Table 4), and one would expect similar stratospheric AoA in these models. However, AoA in the stratosphere is not only determined by the driving meteorological data but also by the treatment of advection (specifically vertical transport), nudging parameters, and the number of vertical layers in the model (Prather et al., 2008). According to a stratospheric AoA study by Diallo et al. (2012), the use of instantaneous wind fields at 3- or 6-hourly time intervals in CTMs may under-sample fast vertical variations during these time intervals. For GCMs that are nudged to reanalysis meteorological data, gravity wave noise may influence the stratospheric AoA. Finally, the vertical coordinate system may influence numerical transport effects (Chipperfield, 2006; Diallo et al., 2012). Other studies on stratospheric AoA (Garny et al., 2014; Ploeger et al., 2015) highlighted the importance of separating stratospheric mixing into a (slow) residual circulation and (fast) eddy mixing. Further analysis on the stratospheric AoA in this model ensemble is, however, left for future exploration.

\subsection{Inter-hemispheric transport}

In this section, we compare the inter-hemispheric transport times using the tracers NHsurface and SHsurface to the simulated latitudinal gradients of $\mathrm{SF}_{6}$. To this end, we show in Fig. $6 \mathrm{a}$ the simulated zonal average latitudinal $\mathrm{SF}_{6}$ gradient at the surface. All gradients have been scaled relative to the South Pole $\mathrm{SF}_{6}$ mixing ratio. Also included in the figure are the latitudinal gradients measured by NOAA/ESRL (Hall et al., 2011). Since the selected model results are averages over all longitudes, including the land masses with high emissions, modelled zonal averages exceed the observations at NH midlatitudes. Most notably, high-altitude stations such as Niwot Ridge (3523 m above sea level (ma.s.l.)) and Mauna Loa (3397 m a.s.l.) show much smaller mixing ratio differences with respect to the South Pole than, for example, Cape Kumukahi at sea level. This is confirmed by panel (b) of Fig. 6, in which the modelled $\mathrm{SF}_{6}$ fields are zonally averaged over the Pacific Ocean only (from 150 to $210^{\circ} \mathrm{E}$ ). In this average all models except NIES agree well within $0.1 \mathrm{pmol} \mathrm{mol}^{-1}$ on the latitudinal gradient. Due to too re-

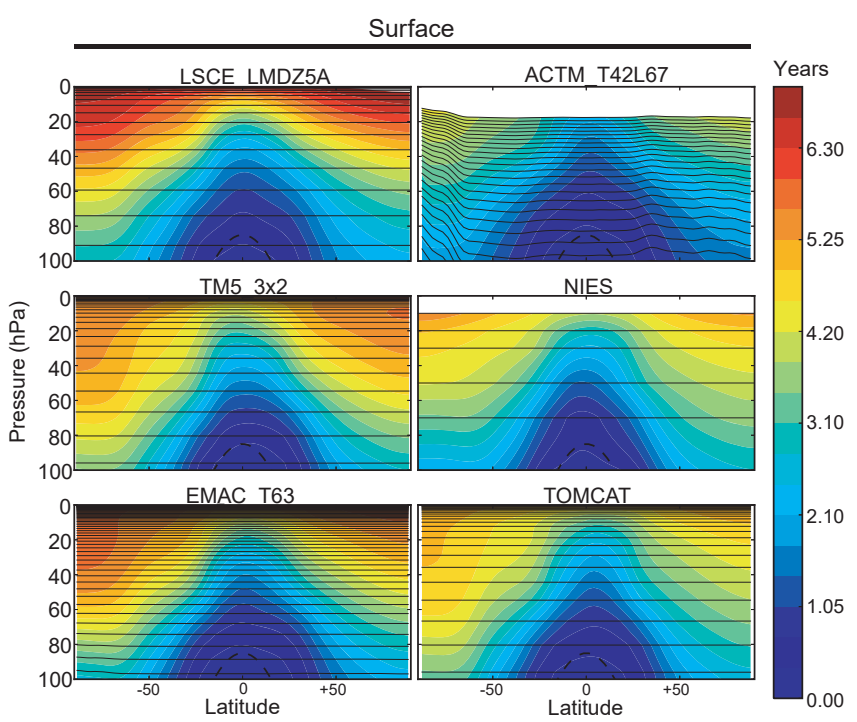

Figure 5. Zonally averaged AoA (years) in the stratosphere for the tracer Surface. The results have been averaged over the period 2000-2010 (11 years). The thin black lines denote the mid-pressure levels of the model. For the ACTM model, this level is at around $17 \mathrm{hPa}$ for the uppermost 50th layer. The dotted black line denotes the climatological tropopause. Note the linear $y$ scale that starts at $100 \mathrm{hPa}$.

duced a vertical mixing combined with fast latitudinal transport, the NIES model underestimates the latitudinal $\mathrm{SF}_{6}$ gradient. The TOMCAT model simulates the observed latitudinal gradient of $\mathrm{SF}_{6}$ on clean background stations well but also shows high accumulation over land (see Figs. 4 and 6a). In Appendix A we further compare the simulated $\mathrm{SF}_{6}$ latitudinal and vertical gradients to measurements made during the HIPPO campaigns (Wofsy et al., 2011).

Panel (c) of Fig. 6 depicts a composite of the AoA of the tracer NHsurface at the SH surface and of the tracer SHsurface at the NH surface. Again, all results are zonal averages over 2000-2010 (11 years) and include all longitudes. Panel (d) of Fig. 6 confirms the NH-SH asymmetry noted earlier in Sect. 3.1 but also makes it clear that the asymmetry differs with model. Panel (d) of Fig. 6 highlights the NH-SH asymmetry by subtracting the NHsurface AoA sampled at the SH surface from the SHsurface AoA sampled at the NH surface. In all models, differences grow gradually from $10^{\circ}$ latitude to the pole, where the AoA differences range between 0.10 years (TM5_3x2) and 0.17 years (EMAC_T106). The model versions with higher spatial resolution (TM5_1x1, EMAC_T106) show larger AoA differences compared to the lower-resolution versions. The TM5 EC-Earth version differs from the other TM5 versions, likely because the physics of the EC-Earth model (IFS version cy36r4) leads to differences in boundary layer mixing and convection, compared to the IFS model version that was used for the ERA-Interim simulation (cy31r2). 

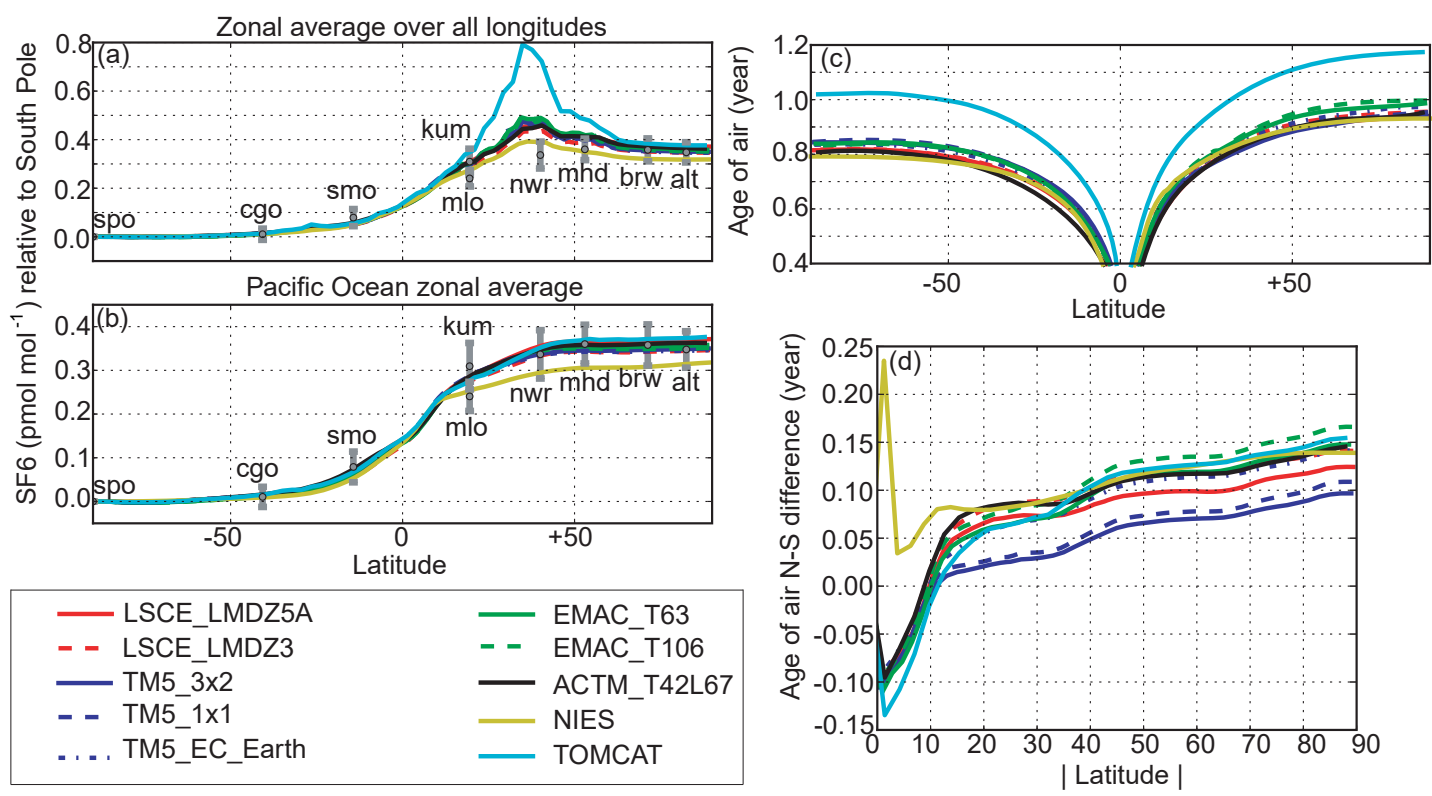

Figure 6. Panels (a) and (b): latitudinal gradient of $\mathrm{SF}_{6}\left(\mathrm{pmol} \mathrm{mol}^{-1}\right)$ at the surface, averaged over 2000-2010 (11 years). Panel (a) includes all longitudes in the modelled zonal average, while panel (b) includes only longitudes over the Pacific Ocean ( 150 to $\left.210^{\circ} \mathrm{E}\right)$. Modelled gradients have been scaled with respect to the South Pole. The grey symbols and their variability are calculated from the combined dataset constructed from flask data measured by the HATS group from NOAA/ESRL and hourly CATS data (https://www.esrl.noaa.gov/gmd/hats/ combined/SF6.html, last access: 6 July 2017). Three-letter codes refer to the stations (alt: Alert, Canada; brw: Pt. Barrow, Alaska, USA; mhd: Mace Head, Ireland; nwr: Niwot Ridge, Colorado, USA; kum: Cape Kumukahi, Hawaii, USA; mlo: Mauna Loa, Hawaii, USA; smo: Cape Matatula, American Samoa; cgo: Cape Grim, Tasmania, Australia; spo: South Pole). Variability is calculated as the standard deviation of monthly time series of the station data relative to the South Pole station. Panel (c): composite of the AoA (years) of the tracer NHsurface at the SH and the tracer SHsurface at the NH (see main text; averaged over 2000-2010). Panel (d): AoA difference (years) calculated from the values of panel (c). The AoA at the SH of the tracer NHsurface is subtracted from the AoA at the NH of the tracer SHsurface and plotted against latitude.

From Fig. 6a and $\mathrm{c}$ it is obvious that the TOMCAT model shows the strongest $\mathrm{SF}_{6}$ gradient, along with the slowest $\mathrm{IH}$ transport as diagnosed from the tracers NHsurface and SHsurface. NIES shows smaller $\mathrm{SF}_{6}$ gradients but IH AoA values in line with other models. Differences between the other models are less pronounced. The gradient of $\mathrm{SF}_{6}$ is driven by emissions that take place mainly at midlatitude land masses in the NH. In contrast, the tracers NHsurface and SHsurface are forced at the entire surface of both hemispheres. To make a meaningful comparison to the simulated latitudinal gradients of $\mathrm{SF}_{6}$, we evaluate the AoA of the tracers NHsurface and SHsurface at $50^{\circ} \mathrm{S}$ and $50^{\circ} \mathrm{N}$, respectively, and at the surface of the models. By adding these two ages, we align the resulting composite AoA with the bulk of the calculated latitudinal $\mathrm{SF}_{6}$ gradient between the South Pole and $50^{\circ} \mathrm{N}$ in panel (b) of Fig. 6. The result is shown in Fig. 7. In this representation, the NIES model deviates by simulating weaker latitudinal $\mathrm{SF}_{6}$ gradients. TOMCAT simulates a similar $\mathrm{SF}_{6}$ gradient compared to other models but differs in the composite AoA. Both models have weak vertical mixing (see Fig. 2), but NIES has fast horizontal transport, while TOMCAT accumulates $\mathrm{SF}_{6}$ over the source regions over land (see Fig. 6a). Different model versions clus- ter together in this representation, but differences between the LMDZ5A and LMDZ3 are larger. This illustrates the impact of the parameterisation of convective mixing in the LMDZ models (see Sect. 2.2).

\subsection{Vertical transport}

In this section, we focus on the vertical transport in the troposphere, as diagnosed from the tracer Land and the simulated vertical gradients of ${ }^{222} \mathrm{Rn}$. To this end, we show in Fig. 8a the simulated mean vertical profiles, area-weighted between $60^{\circ} \mathrm{S}$ and $60^{\circ} \mathrm{N}$ on a log scale. Clearly, the TOMCAT and NIES models retain the ${ }^{222} \mathrm{Rn}$ closer to the surface because of slower vertical mixing. The other models mix the ${ }^{222} \mathrm{Rn}$ to higher altitudes, but larger differences are found at pressures smaller than $400 \mathrm{hPa}$, where some models exhibit stronger increases at 150-300 $\mathrm{hPa}$ (e.g. ACTM, LMDZ5A), associated with the parameterisation of convective mixing. Fig. $8 \mathrm{~b}$ shows the vertical profiles of the AoA of the tracer Land, averaged in the same manner.

To investigate the consistency of differences in vertical mixing between the models, Fig. 9 compares the simulated vertical gradient in ${ }^{222} \mathrm{Rn}$ to the simulated AoA profiles of 


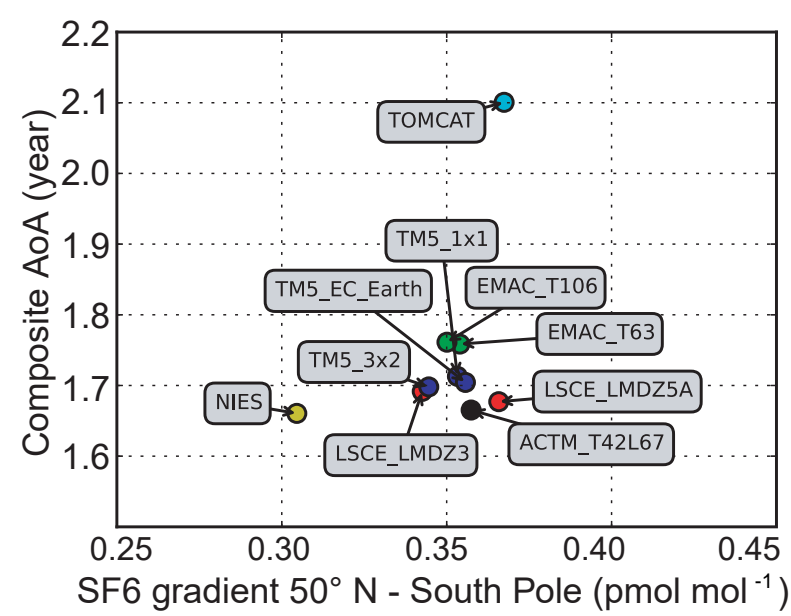

Figure 7. Composite AoA (years) plotted against the modelled $\mathrm{SF}_{6}$ gradient. The composite AoA is calculated as the sum of the $50^{\circ} \mathrm{N}$ AoA of the tracer SHsurface and the $50^{\circ} \mathrm{S}$ AoA of the tracer NHsurface. The $\mathrm{SF}_{6}$ gradient is taken as the concentration difference between $50^{\circ} \mathrm{N}$ and the South Pole from Fig. 6b. Results are averaged over 2000-2010 (11 years).

the tracer Land. Because ${ }^{222} \mathrm{Rn}$ decays radioactively with a half-life of 3.8 days, we convert the vertical gradient of ${ }^{222} \mathrm{Rn}$ mixing ratio as

$\Delta=\ln ^{222} \mathrm{Rn}(950 \mathrm{hPa})-\ln ^{222} \mathrm{Rn}(500 \mathrm{hPa})$,

where we do not sample directly at the surface to avoid differences in sampling strategies between models (see Sect. 2). Here, we quantify the gradient with respect to the $500 \mathrm{hPa}$ level. In Fig. 9 we plot the AoA gradient between 500 and $950 \mathrm{hPa}$ against $\Delta$. The results of the different models show a high degree of linear correlation, indicating that models with efficient vertical mixing (e.g. TM5, ACTM) have small AoA differences between the boundary layer and $500 \mathrm{hPa}$ along with a flatter ${ }^{222} \mathrm{Rn}$ profile. Models with slow vertical mixing (NIES, TOMCAT) show steeper ${ }^{222} \mathrm{Rn}$ profiles along with larger $\Delta$ values. Interestingly, the TM5 and EMAC models show that higher spatial-resolution models lead to faster vertical mixing. This is different to the results found for $\mathrm{IH}$ transport and likely due to the fact that deep convective mixing is a sub-grid-scale process. Numerics of such sub-gridscale processes are less prone to numerical diffusion compared to the advection process that drives the IH gradient. As expected, the two model versions of LMDZ that differ by their convective parameterisation show distinct differences in the vertical profiles.

\subsection{Mapping the tropopause}

Prather et al. (2011) introduced an idealised tracer (E90) to delineate the boundary between troposphere and stratosphere in transport models. Driven by surface emissions and a decay rate of 90 days $^{-1}$, tracer E90 is meant to quantify the

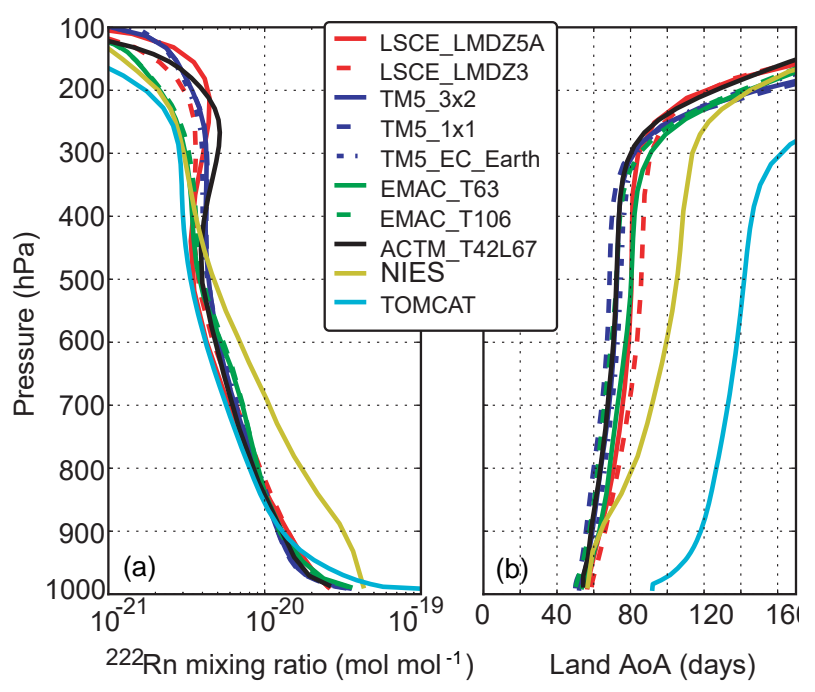

Figure 8. Vertical profiles of ${ }^{222} \mathrm{Rn}\left(\mathbf{a}, \mathrm{mol} \mathrm{mol}^{-1}\right.$, logarithmic axis) and the AoA of the Land tracer (b, in days) simulated by the different models. The vertical profiles have been area-weightedaveraged between $60^{\circ} \mathrm{N}$ and $60^{\circ} \mathrm{S}$ and over the years 2000-2010 (11 years).

rate of mixing of tropospheric air. Through numerical experiments, the tropopause in the UCI CTM (Prather et al., 2011) was defined as the surface on which the mixing ratio of E90 is $90 \mathrm{nmol} \mathrm{mol}^{-1}$. Note that emissions of E90 are defined such that the global stationary state concentration of E90 is $100 \mathrm{nmol} \mathrm{mol}^{-1}$ (see Sect. 2). Mixing ratios in the stratosphere are lower, due to the long transport times. As an alternative to E90, the AoA tracer Surface may also be used to delineate the stratosphere from the troposphere, as shown in Fig. 2. In order to compare the tropopause pressure calculated by either E90 or the AoA surface tracer, we plot the tropopause pressure as a function of latitude in Fig. 10. The tropopause pressure is calculated based on 2000-2010 zonal averages of E90 (unit nmol mol${ }^{-1}$ ) and Surface AoA (unit days). For each latitude the tropopause pressure is determined by interpolation to $\mathrm{E} 90=90 \mathrm{nmol} \mathrm{mol}^{-1}$ (dotted lines in Fig. 10) and to Surface AoA $=90$ days (solid lines in Fig. 10). Results show consistency for these two metrics, although larger differences occur for several models. Differences in tropopause pressure based on E90 and the tracer Surface are likely caused by the transport characteristics of the models. The Surface AoA simulation is forced by linearly increasing boundary conditions which are converted to AoA, while the E90 simulation is driven by surface emissions and a decay process with a 90-day turnover time. This causes different tracer gradients and hence a difference in advective and convective transport. As a result, ACTM calculates systematically higher tropopause pressures for E90, while for NIES the reverse is observed. Other models show similar estimates for both tracers. When models are compared, both tracers calculate similar tropopause pressure 


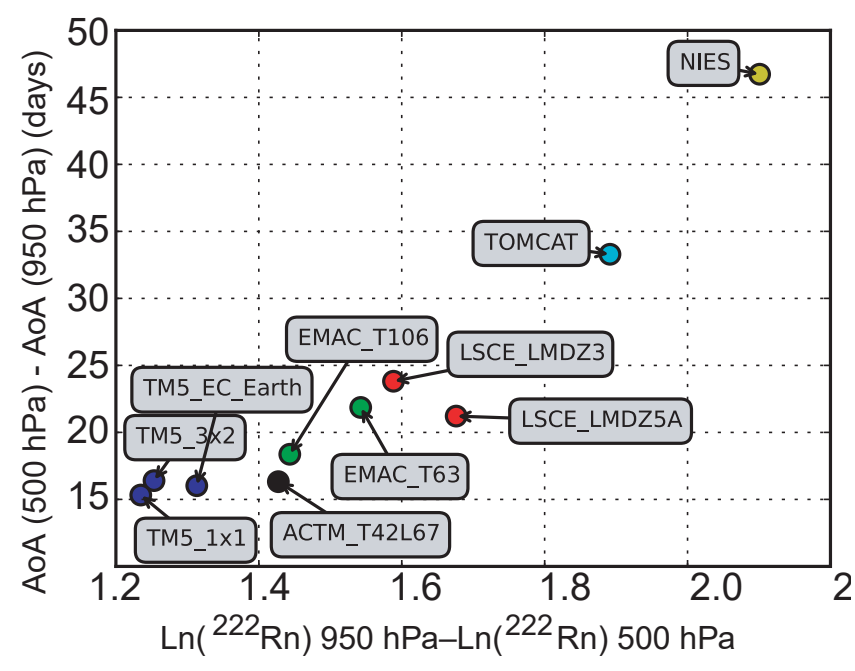

Figure 9. The 500-950 $\mathrm{hPa}$ difference in AoA (days) of the Land tracer plotted against $\Delta:$ a measure for the vertical gradient in ${ }^{222} \mathrm{Rn}$ (see main text). The vertical profiles used for the calculations are shown in Fig. 8.

differences, with NIES showing a very deep tropopause at higher latitudes and TOMCAT a shallower tropopause. Offline models that use the same driver meteorological data (e.g. TOMCAT and TM5) would be expected to have a similar tropopause based on common temperature fields. However, since the tropopause pressures derived here depend on the transport of tracers by advection and convection, substantial differences are found that also depend on the choice of concentration (for tracer E90) and AoA (for the tracer Surface) at which the tropopause is evaluated. Finally, all models agree on a hemispheric asymmetric average tropopause with a tropopause pressure maximum around $55^{\circ} \mathrm{S}$, likely associated with an enhanced stratosphere-stratosphere exchange in the SH (Holton et al., 1995). In most models, this pressure maximum is more pronounced for tracer E90.

\section{Discussion}

This TransCom AoA inter-comparison shows that the tropospheric AoA concept provides useful information on model transport characteristics. It was shown that the IH transport timescale in a particular model is strongly connected to the efficiency of vertical mixing and hence to the specific implementation of sub-grid-scale convective transport. Thus, the AoA metric may be used to better understand flux differences derived from $\mathrm{CO}_{2}$ and $\mathrm{CH}_{4}$ flux inversions (Law et al., 2008; Patra et al., 2011). The NIES model, which has slow convective mixing, still shows fast IH mixing, a small IH $\mathrm{SF}_{6}$ gradient, and a deep extra-tropical tropopause. In contrast, the TOMCAT model in the configuration used here combines weak vertical mixing with a stronger $\mathrm{SF}_{6}$ gradient between land and ocean and a shallower tropopause. The

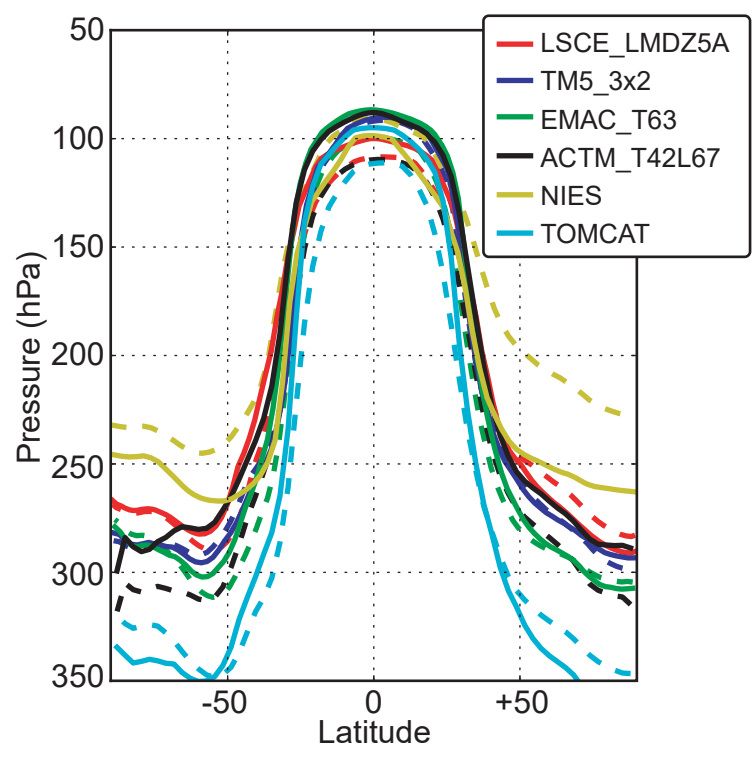

Figure 10. Zonal average tropopause pressure (averaged over 2000 2010) as a function of latitude, obtained from the AoA tracer Surface (solid lines) and E90 (dashed lines) for different models (see legend). Tropopause pressure is obtained from 1-D linear interpolation to 90 days for the AoA tracer Surface and to $90 \mathrm{nmol} \mathrm{mol}^{-1}$ for E90.

TM5 model, which was diagnosed with slow IH transport in the TransCom methane inter-comparison (Patra et al., 2011), now uses the convective fluxes stored in the ECMWF ERAInterim archive, which are based on Gregory et al. (2000) and other changes (Tsuruta et al., 2017; Dee et al., 2011). This brings the IH transport times close to other models (see Fig. 7). This confirms the fact that the parameterisation of sub-grid convective fluxes in CTMs deserves attention, specifically when used in atmospheric inversion studies. This is in line with the study of Stephens et al. (2007), who showed that the attribution of the global $\mathrm{CO}_{2}$ land sink depends strongly on the vertical mixing in models.

We found an interesting hemispheric asymmetry in the IH transport times, with "older" $\mathrm{NH}$ air diagnosed with an AoA tracer forced at the SH surface, compared to the age of SH air, diagnosed with an AoA tracer forced at the NH surface. We tentatively attribute this asymmetry to the effect of land masses in the $\mathrm{NH}$, which lead to an atmospheric stabilisation in winter, decoupling the $\mathrm{BL}$ from the overlying free troposphere (FT). In the AoA protocol, this affects the surface forcing. The situation is reversed in summer, with more efficient mixing over land masses. The resulting net effect is well known as the "seasonal rectifier" (Denning et al., 1995). In Appendix B we present a simplified numerical experiment that shows that the mean AoA in the upper atmosphere shortens with a larger seasonal cycle in near-surface mixing, in line with the asymmetry in IH transport as found in all models. Thus, the AoA metric can also be used to quantify the strength of these rectifier effects in CTMs. Another (related) 
factor that might be responsible for this asymmetry is the mean position of the intertropical convergence zone (ITCZ) north of the equator (Schneider et al., 2014).

A further important timescale in GCMs and CTMs is the mixing time of the BL and its coupling with the overlying FT. Together with the aforementioned "convection" timescale, these two quantities appear responsible for the main model diversity in this inter-comparison. For instance, the TM5 model shows a relatively strong coupling between the $\mathrm{BL}$ and the FT, witnessed by (i) relatively young air of the Ocean AoA tracer over land (Fig. 4), (ii) only a small IH difference in the AoA (Fig. 6d), and (iii) a small $950-500 \mathrm{hPa}$ vertical gradient in ${ }^{222} \mathrm{Rn}$ and the Land AoA tracer (Fig. 9). Differences with the EMAC, LMDZ, and ACTM models seem to be determined by the strength of this BL-FT coupling. Differences with NIES and TOMCAT, however, seem to be driven by differences in the convective parameterisation.

Other model differences, such as resolution, advection scheme, the meteorological driver data, nudging, and the vertical coordinate system may also play a role and may become more apparent on the smaller spatial and temporal scales that are not part of this first analysis. In mapping the tropopause with either E90 or the AoA derived from the surface tracer (Fig. 10), model-dependent differences appeared that may be related to the treatment of atmospheric transport. AoA tracers with a linearly growing boundary condition lead to different concentration gradients than tracers with surface emissions and first-order decay, such as E90. In regions with large gradients, such as the planetary boundary layer and the tropopause, differences in the numerical treatment of advection may lead to different transport characteristic of AoA tracers, compared to tracers with physical sources and sinks.

Our multi-model results agree qualitatively with the study of Waugh et al. (2013) that focused on $\mathrm{SF}_{6}$ and an AoA tracer in a single model (GMI-MERRA). They found older AoA than the age derived from $\mathrm{SF}_{6}$ observations. The AoA simulations presented here allow for more detailed analyses in the future, including comparisons to earlier efforts to quantify tropospheric AoA based on observations (e.g. Holzer and Waugh, 2015).

The simple AoA concept exploited here is easily implemented in CTMs and GCMs, and other modellers are encouraged to implement AoA tracers in their models. The AoA protocol is also useful as a benchmark for model development, similar to Prather et al. (2008). Analysis of AoA simulations performed with a single model with different advection schemes, convective parameterisations, or nudging schemes can be used to study their impact on large-scale transport features, such as IH and vertical transport. AoA studies with a single transport model and different meteorological driver data (e.g. ERA-Interim versus JRA-25) would reveal the potential role of the meteorological driver data on AoA biases. Finally, the entire time series (1988-2015) may be used to study trends in the Brewer-Dobson circulation (Fu et al., 2015) or IH transport timescales.

\section{Conclusions}

This paper presents the first results of the TransCom AoA inter-comparison. Six models simulated five AoA tracers and four additional tracers over the time period 1988-2015. AoA tracers were forced by linearly growing boundary conditions in a predefined atmospheric volume. Advantages of this approach are that (i) the forcing volume can be flexibly chosen and (ii) transport timescales can easily be derived based on simulated mixing ratios that indicate when an air mass was last in contact with the boundary. Disadvantages are that (i) there are no known atmospheric species with linear growing boundary conditions and (ii) artificial mixing ratio gradients introduced close to the forcing volume may be challenging for advection schemes. Successful implementation of the protocol in six global models revealed interesting differences in large-scale transport features. In this paper we mainly analysed averages over the 2000-2010 period. The main findings of this study are as follows:

1. The inter-hemispheric transport time depends strongly on the strength of the convective parameterisation in the participating models. Although convective mixing is identified as a major cause for inter-model differences, other causes, such as the source of reanalysis data, nudging, and advection scheme, cannot be ruled out at the moment. It is recommended to apply the AoA protocol in a single model with different set-ups to study the impact on large-scale transport features.

2. Inter-hemispheric transport proceeds faster from the $\mathrm{NH}$ to the SH than from the SH to the NH. This is attributed to the seasonal rectifier effect caused by $\mathrm{NH}$ land masses, with strong mixing in summer and weak mixing in winter as shown in Appendix B.

3. Boundary layer mixing and venting to the free troposphere over land varies among models, which leads to consistent differences in modelled vertical gradients. The TM5 model shows fast vertical mixing, with consequently relatively young air of the Ocean AoA tracer over land (Fig. 4). In contrast, the TOMCAT model shows slow vertical mixing and old air of the Ocean AoA tracer over land. 
4. The AoA concept can be used to map the tropopause. At the tropopause the air has last been in contact with the surface 90 days ago (AoA $=90$ days). For most models, the derived tropopause pressure is in good agreement with the E90 tracer (Prather et al., 2011).

5. Upper-stratospheric AoA varies considerably among the participating models (4-7 years).

In general, further analysis is required to fully exploit the simulations presented in this paper. For instance, the analysis of inter-annual variations in inter-hemispheric transport and stratospheric AoA may reveal interesting differences between the models. Most of all, further analysis should focus on the causes of the still large spread in the participating models.

Code availability. The AoA protocol and analysis software in the form of a Jupyter Notebook (Python) are available to the community through github (https://github.com/maartenkrol/AoA) and are available at https://doi.org/10.23728/b2share.d6849238d65f435 c8f022221f2107cdd (Krol et al., 2018). The Python notebook aoa_paper.ipynb needs AoA_tools.py. The model output, converted to a standard format, can be downloaded from the ftp location mentioned in AoAprotocol.pdf. Apart from the AoA tracers discussed in this paper, AoA tracers are also available that are forced in the troposphere and stratosphere. These tracers are forced above and below a climatological pressure surface given by Lawrence et al. (2001). Results are not discussed because not all models used the correct definition. Information on the availability of source code for the models featured in this paper is given in Table 5. 


\section{Appendix A: Comparison with HIPPO SF 6}

Figure $\mathrm{A} 1$ compares monthly mean $\mathrm{SF}_{6}$ output from the models to observations made during the HIPPO campaigns (Wofsy et al., 2011). Only HIPPO flights over the Pacific Ocean are included, and the corresponding model mixing ratios are averaged over the Pacific Ocean only (from 150 to $210^{\circ} \mathrm{E}$ ). Hippo 1 observations are compared to monthly means of January 2009, Hippo 2 to November 2009, Hippo 4 to June and July 2011 averages, and Hippo 5 to August 2011. Panel (a) shows the latitudinal gradients averaged over 1$3 \mathrm{~km}$. Since models used different $\mathrm{SF}_{6} 1988$ mixing ratios as initial fields and show different accumulation rates in the lower atmosphere, models have been shifted to match the 2009 observations. Note that the shifts (mentioned in the caption) range from $+1.3 \mathrm{ppt}$ for TOMCAT to $-0.4 \mathrm{ppt}$ for NIES. During the 2009-2011 HIPPO period differences between these two models gradually increase further. This is likely related to fast accumulation in NIES due to limited vertical mixing, combined with fast horizontal transport in the lower atmosphere. TOMCAT was also diagnosed with
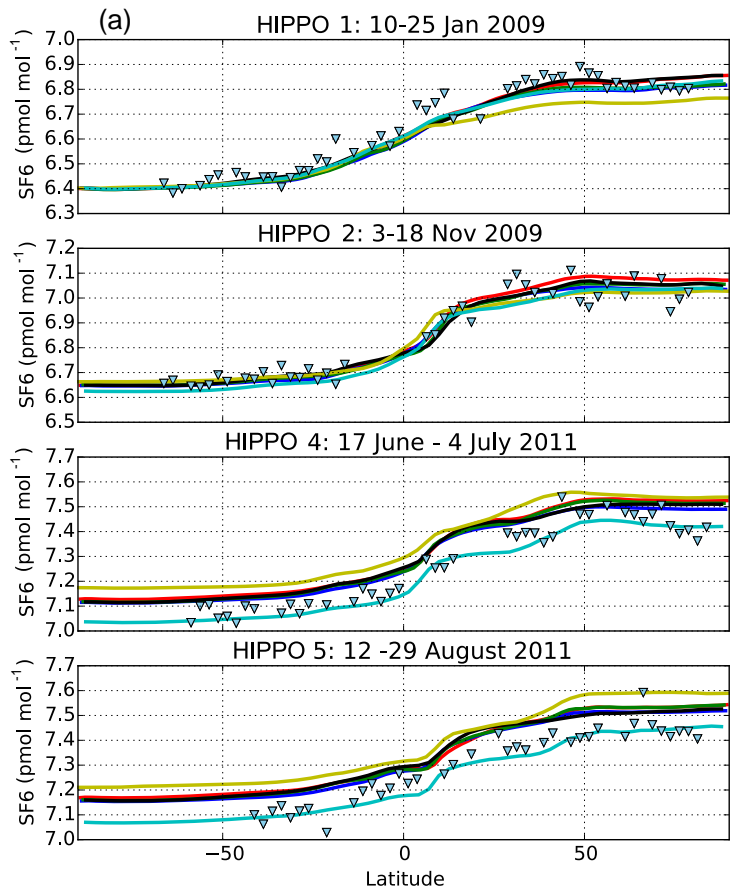

$$
\begin{array}{|lllll}
\hline \nabla & \nabla \text { HIPPO } 1-3 \mathrm{~km} & - & \text { TM5_3 } 32\left(-0.1 \mathrm{pmol} \mathrm{mol}^{-1}\right)-\operatorname{NIES}\left(-0.4 \mathrm{pmol} \mathrm{mol}^{-1}\right) \\
\Delta & \Delta \text { HIPPO } 5-7 \mathrm{~km}-\text { Hippo } 1-3 \mathrm{~km} & - & \text { EMAC_T63 }\left(-0.2 \mathrm{pmol} \mathrm{mol}^{-1}\right)-\text { TOMCAT }\left(1.3 \mathrm{pmol} \mathrm{mol}{ }^{-1}\right) \\
- & \text { LSCE_LMDZ5A }\left(-0.2 \mathrm{pmol} \mathrm{mol}{ }^{-1}\right) & - & \text { ACTM_T42L67 }\left(0.0 \mathrm{pmol} \mathrm{mol}^{-1}\right)
\end{array}
$$

Figure A1. Comparison of modelled monthly-mean $\mathrm{SF}_{6}$ (averaged over the Pacific Ocean only, from 150 to $210^{\circ} \mathrm{E}$ ) to the High-performance Instrumented Airborne Platform for Environmental Research (HIAPER) Pole-to-Pole Observation (HIPPO) campaigns (Wofsy et al., 2011), similar to comparisons presented in Patra et al. (2014). Panel (a) show models and observations averaged over 1-3 km altitude. Panel (b) shows the gradient between 5-7 km averages and 1-3 km averages. Models have been shifted to match the HIPPO latitudinal gradients in 2009. Magnitudes of the shifts are indicated in the caption. 


\section{Appendix B: Seasonal rectifier effect}

The intention of this Appendix is to calculate the effect of seasonal vertical mixing over land on the calculated mean AoA in the upper atmosphere. In the main paper it is speculated that a seasonal rectifier effect partly explains why the AoA derived from SHsurface around the North Pole in the models is $0.10-0.17$ years older than AoA derived from NHsurface around the South Pole (Fig. 6d). With more land cover, seasonality in mixing is stronger in the NH compared to the SH. To illustrate the seasonal rectifier effect, we implemented the AoA protocol in a simplified threebox model. To this end, we force a surface box of $100 \mathrm{~m}$ (pressure difference $\Delta p_{1}$ between bottom and top: $13 \mathrm{hPa}$ ) with a linearly growing mixing ratio as a boundary condition. The surface box mixes with an overlying boundary layer box $\left(\Delta p_{2}=137 \mathrm{hPa}\right)$. This boundary layer box additionally mixes with the overlying free atmosphere $\left(\Delta p_{3}=600 \mathrm{hPa}\right)$. Mixing timescales between the boundary layer and the forced surface layer $\left(\tau_{1}\right)$, and between the boundary layer and free atmosphere $\left(\tau_{2}\right)$ vary with season according to

$$
\begin{aligned}
\tau_{1} & =\left(a_{1} \sin (2 \pi t)+1.0\right) \frac{1}{365}, \\
\tau_{2} & =\left(a_{2} \sin (2 \pi t)+1.0\right) \frac{7}{365},
\end{aligned}
$$

where time $t$ is measured in years and $a_{1}$ and $a_{2}$ are the amplitudes of the seasonal cycles imposed on the standard mixing timescales $\tau_{1}$ and $\tau_{2}$ of 1 and 7 days, respectively. The following set of differential equations is solved to simulate the mixing ratios $x_{1}, x_{2}$, and $x_{3}$ according to the AoA protocol:

$$
\begin{aligned}
\frac{\mathrm{d} x_{1}}{\mathrm{~d} t} & =1, \\
\frac{\mathrm{d} x_{2}}{\mathrm{~d} t} & =\frac{x_{1}-x_{2}}{\tau_{1}}-\frac{x_{2}-x_{3}}{\tau_{2}}, \\
\frac{\mathrm{d} x_{3}}{\mathrm{~d} t} & =\frac{\Delta p_{2}}{\Delta p_{3}} \frac{x_{2}-x_{3}}{\tau_{2}},
\end{aligned}
$$

where $\frac{\Delta p_{2}}{\Delta p_{3}}$ accounts for the fact that boxes 2 and 3 have different pressure thicknesses. We now performed two simulations: one representing the $\mathrm{SH}$ with no seasonal cycle in mixing $\left(a_{1}=a_{2}=0\right)$ and one representing the $\mathrm{NH}$, with a $50 \%$ amplitude in seasonal mixing $\left(a_{1}=a_{2}=0.5\right)$. Results of the simulations, with mixing ratios converted into AoA units $(\mathrm{AoA}=t-x)$, are plotted in Fig. B1a. As expected, $\mathrm{NH}$ AoA (solid lines) shows a seasonal cycle in the boundary layer and free atmosphere, while the SH simulation (dotted lines) reaches a steady-state AoA in the free atmosphere of about 37 days, roughly in line with the multi-year averaged AoA of the tracer Surface in Fig. 2. Figure B1b shows the percentage difference in the 1-year moving average of the $\mathrm{NH}$ and $\mathrm{SH}$ simulations, calculated as $100 \times \frac{\mathrm{SH}-\mathrm{NH}}{\mathrm{NH}}$. Indeed, the average AoA in the free atmosphere and boundary
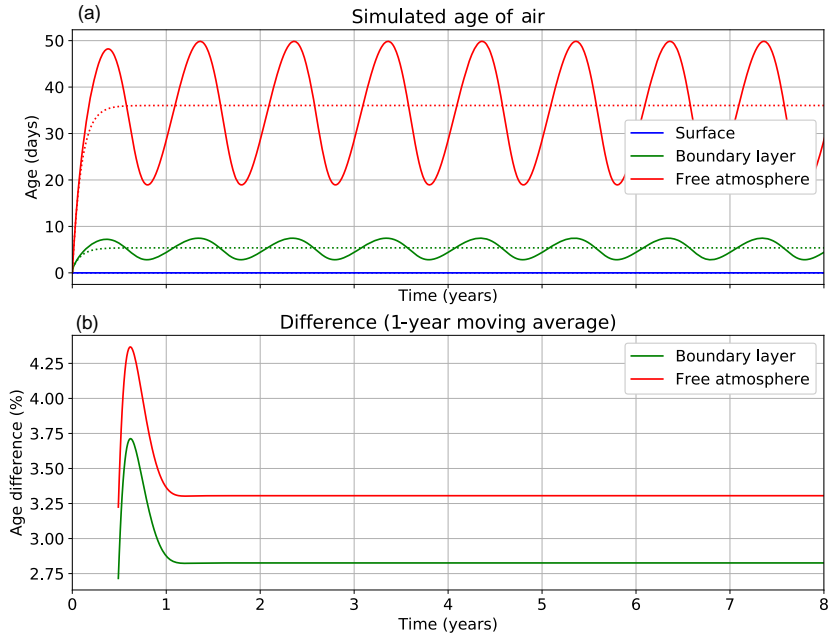

Figure B1. Panel (a): simulated AoA in the simple three-box model described in the main text. The solid lines show the NH simulation with a $50 \%$ seasonal cycle in vertical mixing. The dotted lines show the SH simulation with no seasonal cycle in vertical mixing. Panel (b): difference in the 1-year moving average AoA calculated as $100 \times \frac{\mathrm{SH}-\mathrm{NH}}{\mathrm{NH}}$.

layer is younger by about $3 \%$ when a seasonal cycle is applied to the vertical mixing. Thus, even when the mean mixing timescales between the boxes are the same, the resulting mean AoA in the upper atmosphere is different. In a real atmosphere, other factors may also play a role, such as convection and the asymmetry in the mean position of the ITCZ north of the equator (Schneider et al., 2014). Nevertheless, this simple example shows that a rectifier effect may partly explain the asymmetry in inter-hemispheric mixing as seen in all models (Fig. 3). 
Author contributions. MK wrote the paper and incorporated revisions and comments from all co-authors. MdB performed the TM5 simulations and LK the TM5_EC-Earth simulations. HO and AP were responsible for EMAC, YY, FC, and PB for LMDZ, PP for ACTM, DB and SM for NIES, and SD, WF, and MPC for TOMCAT. The protocol was initiated by MK and PP.

Competing interests. The authors declare that they have no conflict of interest.

Acknowledgements. We thank the HIPPO science team and the crew and support staff at the NCAR Research Aviation Facility, and all the laboratory staff working for AGAGE and NOAA measurement networks. The TM5 model simulations and analysis were carried out on the Dutch national e-infrastructure with the support of SURF Cooperative. Marco de Bruine is supported by the Netherlands Organization for Scientific Research (NWO), project number GO/13-01. The TOMCAT simulations were performed on the UK Archer and Leeds ARC HPC facilities. Dmitry Belikov is supported by the Japan Society for the Promotion of Science, Grant-in-Aid for Scientific Research (S) 26220101. Maarten Krol is supported by ERC AdG grant 742798. Paul Palmer is acknowledged for support of the initial AoA initiative.

Edited by: Slimane Bekki

Reviewed by: Michael Prather and one anonymous referee

\section{References}

Arakawa, A. and Schubert, W. H.: Interaction of a Cumulus Cloud Ensemble with the Large-Scale Environment, Part I, J. Atmos. Sci., 31, 674-701, 1974.

Austin, P. M. and Houze Jr., R. A.: A technique for computing vertical transports by precipitating cumuli, J. Atmos. Sci., 30, 11001111, 1973.

Bândă, N., Krol, M., Noije, T., Weele, M., Williams, J. E., Sager, P. L., Niemeier, U., Thomason, L., and Rockmann, T.: The effect of stratospheric sulfur from Mount Pinatubo on tropospheric oxidizing capacity and methane, J. Geophys. Res.-Atmos., 120, 1202-1220, 2015.

Belikov, D. A., Maksyutov, S., Krol, M., Fraser, A., Rigby, M., Bian, H., Agusti-Panareda, A., Bergmann, D., Bousquet, P., Cameron-Smith, P., Chipperfield, M. P., Fortems-Cheiney, A., Gloor, E., Haynes, K., Hess, P., Houweling, S., Kawa, S. R., Law, R. M., Loh, Z., Meng, L., Palmer, P. I., Patra, P. K., Prinn, R. G., Saito, R., and Wilson, C.: Off-line algorithm for calculation of vertical tracer transport in the troposphere due to deep convection, Atmos. Chem. Phys., 13, 1093-1114, https://doi.org/10.5194/acp-13-1093-2013, 2013a.

Belikov, D. A., Maksyutov, S., Sherlock, V., Aoki, S., Deutscher, N. M., Dohe, S., Griffith, D., Kyro, E., Morino, I., Nakazawa, T., Notholt, J., Rettinger, M., Schneider, M., Sussmann, R., Toon, G. C., Wennberg, P. O., and Wunch, D.: Simulations of columnaveraged $\mathrm{CO}_{2}$ and $\mathrm{CH}_{4}$ using the NIES TM with a hybrid sigmaisentropic $(\sigma-\theta)$ vertical coordinate, Atmos. Chem. Phys., 13, 1713-1732, https://doi.org/10.5194/acp-13-1713-2013, 2013.
Bergamaschi, P., Houweling, S., Segers, A., Krol, M., Frankenberg, C., Scheepmaker, R. A., Dlugokencky, E., Wofsy, S. C., Kort, E. A., Sweeney, C., Schuck, T., Brenninkmeijer, C., Chen, H., Beck, V., and Gerbig, C.: Atmospheric $\mathrm{CH}_{4}$ in the first decade of the 21 st century: Inverse modeling analysis using SCIAMACHY satellite retrievals and NOAA surface measurements, J. Geophys. Res., 118, 7350-7369, 2013.

Berthet, G., Esler, J. G., and Haynes, P. H.: A Lagrangian perspective of the tropopause and the ventilation of the lowermost stratosphere, J. Geophys. Res., 112, D18102, https://doi.org/10.1029/2006JD008295, 2007.

Boucher, O., Friedlingstein, P., Collins, B., and Shine, K. P.: The indirect global warming potential and global temperature change potential due to methane oxidation, Environ. Res. Lett., 4, 044007, https://doi.org/10.1088/1748-9326/4/4/044007, 2009.

Butchart, N.: The Brewer-Dobson circulation, Rev. Geophys., 52, 157-184, https://doi.org/10.1002/2013RG000448, 2014.

Chevallier, F.: On the statistical optimality of $\mathrm{CO}_{2}$ atmospheric inversions assimilating $\mathrm{CO}_{2}$ column retrievals, Atmos. Chem. Phys., 15, 11133-11145, https://doi.org/10.5194/acp-15-111332015, 2015.

Chiaki, K. and Toshiki, I.: Brewer-Dobson circulation diagnosed from JRA-55, J. Geophys. Res.-Atmos., 121, 1493-1510, 1016.

Chipperfield, M. P.: New version of the TOMCAT/SLIMCAT offline chemical transport model: Intercomparison of stratospheric tracer experiments, Q. J. Roy. Meteor. Soc., 132, 1179-1203, 2006.

Chipperfield, M. P., Dhomse, S. S., Feng, W., McKenzie, R. L., Velders, G. J. M., and Pyle, J. A.: Quantifying the ozone and ultraviolet benefits already achieved by the Montreal Protocol, Nat. Commun., 6, 8032, https://doi.org/10.1038/ncomms8233, 2015.

Colella, P. and Woodward, P. R.: The Piecewise Parabolic Method (PPM) for gas-dynamical simulations, J. Comput. Phys., 54, 174-201, 1984.

Deardorff, J. W.: The Counter-Gradient Heat Flux in the Lower Atmosphere and in the Laboratory, J. Atmos. Sci., 23, 503-506, 1966.

Dee, D. P., Uppala, S. M., Simmons, A. J., Berrisford, P., Poli, P., Kobayashi, S., Andrae, U., Balmaseda, M. A., Balsamo, G., Bauer, P., Bechtold, P., Beljaars, A. C. M., van de Berg, L., Bidlot, J., Bormann, N., Delsol, C., Dragani, R., Fuentes, M., Geer, A. J., Haimberger, L., Healy, S. B., Hersbach, H., Hólm, E. V., Isaksen, L., Kållberg, P., Köhler, M., Matricardi, M., McNally, A. P., Monge-Sanz, B. M., Morcrette, J. J., Park, B. K., Peubey, C., de Rosnay, P., Tavolato, C., Thépaut, J. N., and Vitart, F.: The ERA-Interim reanalysis: configuration and performance of the data assimilation system, Q. J. Roy. Meteor. Soc., 137, 553-597, 2011.

Denning, A. S., Fung, I. Y., and Randall, D.: Latitudinal gradient of atmospheric $\mathrm{CO}_{2}$ due to seasonal exchange with land biota, Nature, 376, 240-243, 1995.

Denning, A. S., Holzer, M., Gurney, K. R., Heimann, M., Law, R. M., Rayner, P. J., Fung, I. Y., Fan, S. M., Taguchi, S., Friedlingstein, P., Balkanski, Y., Taylor, J., Maiss, M., and Levin, I.: Three-dimensional transport and concentration of SF6, Tellus Ser. B, 51, 266-297, 1999.

Diallo, M., Legras, B., and Chédin, A.: Age of stratospheric air in the ERA-Interim, Atmos. Chem. Phys., 12, 12133-12154, https://doi.org/10.5194/acp-12-12133-2012, 2012. 
Emanuel, K. A.: A Scheme for Representing Cumulus Convection in Large-Scale Models, J. Atmos. Sci., 48, 2313-2329, 1991.

Engel, A., Moebius, T., Boenisch, H., Schmidt, U., Heinz, R., Levin, I., Atlas, E., Aoki, S., Nakazawa, T., Sugawara, S., Moore, F., Hurst, D., Elkins, J., Schauffler, S., Andrews, A., and Boering, K.: Age of stratospheric air unchanged within uncertainties over the past 30 years, Nat. Geosci., 2, 28-31, 2009.

Feng, W., Chipperfield, M. P., Dhomse, S., Monge-Sanz, B. M., Yang, X., Zhang, K., and Ramonet, M.: Evaluation of cloud convection and tracer transport in a three-dimensional chemical transport model, Atmos. Chem. Phys., 11, 5783-5803, https://doi.org/10.5194/acp-11-5783-2011, 2011.

Francey, R. J. and Frederiksen, J. S.: The 2009-2010 step in atmospheric $\mathrm{CO}_{2}$ interhemispheric difference, Biogeosciences, 13, 873-885, https://doi.org/10.5194/bg-13-873-2016, 2016.

Fu, Q., Lin, P., Solomon, S., and Hartmann, D. L.: Observational evidence of strengthening of the Brewer-Dobson circulation since 1980, J. Geophys. Res.-Atmos., 120, 10214-10228, 2015.

Garny, H., Birner, T., Boenisch, H., and Bunzel, F.: The effects of mixing on age of air, J. Geophys. Res., 119, 7015-7034, 2014.

Gloor, M., Dlugokencky, E., Brenninkmeijer, C., Horowitz, L., Hurst, D. F., Dutton, G., Crevoisier, C., Machida, T., and Tans, P.: Three-dimensional SF6 data and tropospheric transport simulations: Signals, modeling accuracy, and implications for inverse modeling, J. Geophys. Res., 112, D15112, https://doi.org/10.1029/2006JD007973, 2007.

Gregory, D., Morcrette, J. J., Jakob, C., Beljaars, A. C. M., and Stockdale, T.: Revision of convection, radiation and cloud schemes in the ECMWF integrated forecasting system, Q. J. Roy. Meteor. Soc., 126, 1685-1710, 2000.

Grell, A., Dudhia, J., and Stauffer, D.: A description of the fifth-generation Penn State/NCAR Mesoscale Model (MM5), NCAR Technical Note NCAR/TN 398+STR, https://doi.org/10.5065/D60Z716B, 1994.

Hack, J. J., Boville, B. A., Briegleb, B. P., Kiehl, J. T., Rasch, P. J., and Williamson, D. L.: Description of the NCAR community climate model (CCM2), Tech. rep., NCAR, Boulder, USA, 1993.

Hall, B. D., Dutton, G. S., Mondeel, D. J., Nance, J. D., Rigby, M., Butler, J. H., Moore, F. L., Hurst, D. F., and Elkins, J. W.: Improving measurements of $\mathrm{SF}_{6}$ for the study of atmospheric transport and emissions, Atmos. Meas. Tech., 4, 2441-2451, https://doi.org/10.5194/amt-4-2441-2011, 2011.

Hall, T. M. and Plumb, R. A.: Age as a diagnostic of stratospheric transport, J. Geophys. Res., 99, 1059-1070, 1994.

Hall, T. M. and Prather, M. J.: Simulations of the trend and annual cycle in stratospheric $\mathrm{CO}_{2}$, J. Geophys. Res.-Atmos., 98, 1057310581, 1993.

Hall, T. M., Waugh, D. W., Boering, K., and Plumb, R. A.: Evaluation of transport in stratospheric models, J. Geophys. Res., 104, 18815-18839, 1999.

Hazeleger, W., Severijns, C., Semmler, T., Ştefănescu, S., Yang, S., Wang, X., Wyser, K., Dutra, E., Baldasano, J. M., Bintanja, R., Bougeault, P., Caballero, R., Ekman, A. M. L., Christensen, J. H., van den Hurk, B., Jimenez, P., Jones, C., Kållberg, P., Koenigk, T., McGrath, R., Miranda, P., van Noije, T., Palmer, T., Parodi, J. A., Schmith, T., Selten, F., Storelvmo, T., Sterl, A., Tapamo, H., Vancoppenolle, M., Viterbo, P., and Willén, U.: EC-Earth: A Seamless Earth-System Prediction Approach in Action, B. Am. Meteorol. Soc., 91, 1357-1363, 2010.
Hazeleger, W., Wang, X., Severijns, C., Ştefănescu, S., Bintanja, R., Sterl, A., Wyser, K., Semmler, T., Yang, S., van den Hurk, B., van Noije, T., van der Linden, E., and van der Wiel, K.: EC-Earth V2.2: description and validation of a new seamless earth system prediction model, Clim. Dynam., 39, 2611-2629, 2012.

Holton, J. R., Haynes, P. H., McIntyre, M. E., Douglass, A. R., Rood, R. B., and Pfister, L.: Stratosphere-troposphere exchange, Rev. Geophys., 33, 403-439, 1995.

Holtslag, A. A. M. and Boville, B. A.: Local Versus Nonlocal Boundary-Layer Diffusion in a Global Climate Model, J. Climate, 6, 1825-1842, 1993

Holzer, M. and Hall, T. M.: Transit-Time and Tracer-Age Distributions in Geophysical Flows, J. Atmos. Sci., 57, 3539-3558, 2000.

Holzer, M. and Waugh, D. W.: Interhemispheric transit time distributions and path-dependent lifetimes constrained by measurements of $\mathrm{SF}_{6}, \mathrm{CFCs}$, and CFC replacements, Geophys. Res. Lett., 42, 4581-4589, 2015.

Hoor, P., Wernli, H., Hegglin, M. I., and Bönisch, H.: Transport timescales and tracer properties in the extratropical UTLS, Atmos. Chem. Phys., 10, 7929-7944, https://doi.org/10.5194/acp10-7929-2010, 2010.

Hourdin, F., Musat, I., Bony, S., Braconnot, P., Codron, F., Dufresne, J.-L., Fairhead, L., Filiberti, M.-A., Friedlingstein, P., Grandpeix, J.-Y., Krinner, G., LeVan, P., Li, Z.-X., and Lott, F.: The LMDZ4 general circulation model: climate performance and sensitivity to parametrized physics with emphasis on tropical convection, Clim. Dynam., 27, 787-813, 2006.

Hourdin, F., Grandpeix, J.-Y., Rio, C., Bony, S., Jam, A., Cheruy, F., Rochetin, N., Fairhead, L., Idelkadi, A., Musat, I., Dufresne, J.L., Lahellec, A., Lefebvre, M.-P., and Roehrig, R.: LMDZ5B: the atmospheric component of the IPSL climate model with revisited parameterizations for clouds and convection, Clim. Dynam., 40, 2193-2222, 2012.

Houweling, S., Krol, M., Bergamaschi, P., Frankenberg, C., Dlugokencky, E. J., Morino, I., Notholt, J., Sherlock, V., Wunch, D., Beck, V., Gerbig, C., Chen, H., Kort, E. A., Röckmann, T., and Aben, I.: A multi-year methane inversion using SCIAMACHY, accounting for systematic errors using TCCON measurements, Atmos. Chem. Phys., 14, 3991-4012, https://doi.org/10.5194/acp-14-3991-2014, 2014

Hsu, J. and Prather, M. J.: Is the residual vertical velocity a good proxy for stratosphere-troposphere exchange of ozone?, Geophys. Res. Lett., 41, 9024-9032, 2014.

Huijnen, V., Williams, J., van Weele, M., van Noije, T., Krol, M., Dentener, F., Segers, A., Houweling, S., Peters, W., de Laat, J., Boersma, F., Bergamaschi, P., van Velthoven, P., Le Sager, P., Eskes, H., Alkemade, F., Scheele, R., Nédélec, P., and Pätz, H.-W.: The global chemistry transport model TM5: description and evaluation of the tropospheric chemistry version 3.0, Geosci. Model Dev., 3, 445-473, https://doi.org/10.5194/gmd-3445-2010, 2010.

Jacob, D. J., Prather, M. J., Rasch, P. J., Shia, R. L., Balkanski, Y. J., Beagley, S. R., Bergmann, D. J., Blackshear, W. T., Brown, M., Chiba, M., Chipperfield, M. P., Grandpré, J., Dignon, J. E., Feichter, J., Genthon, C., Grose, W. L., Kasibhatla, P. S., Köhler, I., Kritz, M. A., Law, K., Penner, J. E., Ramonet, M., Reeves, C. E., Rotman, D. A., Stockwell, D. Z., van Velthoven, P. F. J., Verver, G., Wild, O., Yang, H., and Zimmermann, P.: Evaluation and intercomparison of global atmospheric transport mod- 
els using 222Rn and other short-lived tracers, J. Geophys. Res.Atmos., 102, 5953-5970, 1997.

Jeuken, A. B. M., Siegmund, P. C., Heijboer, L. C., Feichter, J., and Bengtsson, L.: On the potential of assimilating meteorological analyses in a global climate model for the purpose of model validation, J. Geophys. Res.-Atmos., 101, 16939-16950, 1996.

Jöckel, P., Sander, R., Kerkweg, A., Tost, H., and Lelieveld, J.: Technical Note: The Modular Earth Submodel System (MESSy) - a new approach towards Earth System Modeling, Atmos. Chem. Phys., 5, 433-444, https://doi.org/10.5194/acp-5-4332005, 2005.

Jöckel, P., Tost, H., Pozzer, A., Brühl, C., Buchholz, J., Ganzeveld, L., Hoor, P., Kerkweg, A., Lawrence, M. G., Sander, R., Steil, B., Stiller, G., Tanarhte, M., Taraborrelli, D., van Aardenne, J., and Lelieveld, J.: The atmospheric chemistry general circulation model ECHAM5/MESSy1: consistent simulation of ozone from the surface to the mesosphere, Atmos. Chem. Phys., 6, 50675104, https://doi.org/10.5194/acp-6-5067-2006, 2006.

Jöckel, P., Kerkweg, A., Pozzer, A., Sander, R., Tost, H., Riede, H., Baumgaertner, A., Gromov, S., and Kern, B.: Development cycle 2 of the Modular Earth Submodel System (MESSy2), Geosci. Model Dev., 3, 717-752, https://doi.org/10.5194/gmd-3717-2010, 2010.

Karstens, U., Schwingshackl, C., Schmithüsen, D., and Levin, I.: A process-based ${ }^{222}$ radon flux map for Europe and its comparison to long-term observations, Atmos. Chem. Phys., 15, 1284512865, https://doi.org/10.5194/acp-15-12845-2015, 2015.

Kovács, T., Feng, W., Totterdill, A., Plane, J. M. C., Dhomse, S., Gómez-Martín, J. C., Stiller, G. P., Haenel, F. J., Smith, C., Forster, P. M., García, R. R., Marsh, D. R., and Chipperfield, M. P.: Determination of the atmospheric lifetime and global warming potential of sulfur hexafluoride using a three-dimensional model, Atmos. Chem. Phys., 17, 883-898, https://doi.org/10.5194/acp-17-883-2017, 2017.

Krol, M., Houweling, S., Bregman, B., van den Broek, M., Segers, A., van Velthoven, P., Peters, W., Dentener, F., and Bergamaschi, P.: The two-way nested global chemistry-transport zoom model TM5: algorithm and applications, Atmos. Chem. Phys., 5, 417432, https://doi.org/10.5194/acp-5-417-2005, 2005.

Krol, M., Peters, W., Hooghiemstra, P., George, M., Clerbaux, C., Hurtmans, D., McInerney, D., Sedano, F., Bergamaschi, P., El Hajj, M., Kaiser, J. W., Fisher, D., Yershov, V., and Muller, J.-P.: How much CO was emitted by the 2010 fires around Moscow?, Atmos. Chem. Phys., 13, 4737-4747, https://doi.org/10.5194/acp-13-4737-2013, 2013.

Krol, M., de Bruine, M., Killaars, L., Ouwersloot, H., Pozzer, A., Yin, Y., Chevallier, F., Bousquet, P., Patra, P., Belikov, D., Maksyutov, S., Dhomse, S., Feng, W., and Chipperfield, M. P.: AoA.zip, https://doi.org/10.23728/b2share.d6849238d65f435 c8f022221f2107cdd, 2018.

Law, R. M., Rayner, P. J., Denning, A. S., Erickson, D., Fung, I. Y., Heimann, M., Piper, S. C., Ramonet, M., Taguchi, S., Taylor, J. A., Trudinger, C. M., and Watterson, I. G.: Variations in modeled atmospheric transport of carbon dioxide and the consequences for $\mathrm{CO}_{2}$ inversions, Global Biogeochem. Cy., 10, 783796, 1996.

Law, R. M., Peters, W., Rödenbeck, C., Aulagnier, C., Baker, I., Bergmann, D. J., Bousquet, P., Brandt, J., Bruhwiler, L., Cameron-Smith, P. J., Christensen, J. H., Delage, F., Den- ning, A. S., Fan, S., Geels, C., Houweling, S., Imasu, R., Karstens, U., Kawa, S. R., Kleist, J., Krol, M. C., Lin, S. J., Lokupitiya, R., Maki, T., Maksyutov, S., Niwa, Y., Onishi, R., Parazoo, N., Patra, P. K., Pieterse, G., Rivier, L., Satoh, M., Serrar, S., Taguchi, S., Takigawa, M., Vautard, R., Vermeulen, A. T., and Zhu, Z.: TransCom model simulations of hourly atmospheric $\mathrm{CO}_{2}$ : Experimental overview and diurnal cycle results for 2002, Global Biogeochem. Cy., 22, GB3009, https://doi.org/10.1029/2007GB003050, 2008.

Lawrence, M. G., Jöckel, P., and von Kuhlmann, R.: What does the global mean $\mathrm{OH}$ concentration tell us?, Atmos. Chem. Phys., 1, 37-49, https://doi.org/10.5194/acp-1-37-2001, 2001.

Levin, I., Naegler, T., Heinz, R., Osusko, D., Cuevas, E., Engel, A., Ilmberger, J., Langenfelds, R. L., Neininger, B., Rohden, C. v., Steele, L. P., Weller, R., Worthy, D. E., and Zimov, S. A.: The global $\mathrm{SF}_{6}$ source inferred from long-term high precision atmospheric measurements and its comparison with emission inventories, Atmos. Chem. Phys., 10, 2655-2662, https://doi.org/10.5194/acp-10-2655-2010, 2010.

Lin, S.-J. and Rood, R. B.: Multidimensional Flux-Form SemiLagrangian Transport Schemes, Mon. Weather Rev., 124, 20462070, 1996.

Locatelli, R., Bousquet, P., Hourdin, F., Saunois, M., Cozic, A., Couvreux, F., Grandpeix, J.-Y., Lefebvre, M.-P., Rio, C., Bergamaschi, P., Chambers, S. D., Karstens, U., Kazan, V., van der Laan, S., Meijer, H. A. J., Moncrieff, J., Ramonet, M., Scheeren, H. A., Schlosser, C., Schmidt, M., Vermeulen, A., and Williams, A. G.: Atmospheric transport and chemistry of trace gases in LMDz5B: evaluation and implications for inverse modelling, Geosci. Model Dev., 8, 129-150, https://doi.org/10.5194/gmd-8129-2015, 2015a.

Locatelli, R., Bousquet, P., Saunois, M., Chevallier, F., and Cressot, C.: Sensitivity of the recent methane budget to LMDz subgrid-scale physical parameterizations, Atmos. Chem. Phys., 15, 9765-9780, https://doi.org/10.5194/acp-15-9765-2015, $2015 \mathrm{~b}$.

Louis, J. F.: A parametric model of vertical eddy fluxes in the atmosphere, Bound.-Lay. Meteorol., 17, 187-202, 1979.

Maksyutov, S. and Inoue, G.: Global tracer transport model simulations of $\mathrm{CO}_{2}$ variations over Eurasia, Tech. Rep. v.6-1997, CGER, NIES, Japan, 1999.

Mellor, G. L. and Yamada, T.: A Hierarchy of Turbulence Closure Models for Planetary Boundary Layers, J. Atmos. Sci., 31, 17911806, 1974.

Molteni, F., Stockdale, T., Balmaseda, M. A., Balsamo, G., Buizza, R., Ferranti, L., Magnusson, L., Mogensen, K., Palmer, T. N., and Vitart, F.: The new ECMWF seasonal forecast system (System 4), European Centre for Medium-Range Weather Forecasts, Reading, UK, 2011.

Monks, S. A., Arnold, S. R., Hollaway, M. J., Pope, R. J., Wilson, C., Feng, W., Emmerson, K. M., Kerridge, B. J., Latter, B. L., Miles, G. M., Siddans, R., and Chipperfield, M. P.: The TOMCAT global chemical transport model v1.6: description of chemical mechanism and model evaluation, Geosci. Model Dev., 10, 3025-3057, https://doi.org/10.5194/gmd-10-3025-2017, 2017.

Myhre, G., Shindell, D., Bréon, J.-M., Collins, W., Fuglestvedt, J., Huang, J., Koch, D., Lamarque, J.-F., Lee, D., Mendoza, B., Nakajima, T., Robock, A., Stephens, G., Takemura, T., and Zhang, H.: Anthropogenic and Natural Radiative Forcing, in: Climate Change 2013 - The Physical Science Basis, edited by: 
Stocker, T. F., Qin, D., Plattner, G. K., Tignor, M., Allen, S. K., Boschung, J., Nauels, A., Xia, Y., Bex, V., and Midgley, P. M., Cambridge University Press, Cambridge, 659-740, 2013.

Neu, J. L. and Plumb, R. A.: Age of air in a "leaky pipe" model of stratospheric transport, J. Geophys. Res.-Atmos., 104, 1924319255, 1999.

Numaguti, A., Takahashi, M., Nakajima, T., and Sumi, A.: Description of CCSR/NIES Atmospheric General Circulation Model, Tech. rep., Center for Global Environmental Research. National Institute for Environmental Studies, 1997.

Onogi, K., Tsutsui, J., Koide, H., Sakamoto, M., Kobayashi, S., Hatsushika, H., Matsumoto, T., Yamazaki, N., Kamahori, H., Takahashi, K., Kadokura, S., Wada, K., Kato, K., Oyama, R., Ose, T., Mannoji, N., and Taira, R.: The JRA-25 Reanalysis, J. Meteorol. Soc. Jpn., 85, 369-432, 2007.

Ouwersloot, H. G., Pozzer, A., Steil, B., Tost, H., and Lelieveld, J.: Revision of the convective transport module CVTRANS 2.4 in the EMAC atmospheric chemistry-climate model, Geosci. Model Dev., 8, 2435-2445, https://doi.org/10.5194/gmd-8-24352015, 2015.

Pandey, S., Houweling, S., Krol, M., Aben, I., Monteil, G., NechitaBanda, N., Dlugokencky, E. J., Detmers, R., Hasekamp, O., Xu, X., Riley, W. J., Poulter, B., Zhang, Z., McDonald, K. C., White, J. W. C., Bousquet, P., and Rockmann, T.: Enhanced methane emissions from tropical wetlands during the $2011 \mathrm{La}$ Niña, Nature Publishing Group, 7, 1-8, 2017.

Patra, P. K., Takigawa, M., Dutton, G. S., Uhse, K., Ishijima, K., Lintner, B. R., Miyazaki, K., and Elkins, J. W.: Transport mechanisms for synoptic, seasonal and interannual $\mathrm{SF}_{6}$ variations and "age" of air in troposphere, Atmos. Chem. Phys., 9, 1209-1225, https://doi.org/10.5194/acp-9-1209-2009, 2009a.

Patra, P. K., Takigawa, M., Ishijima, K., Choi, B.-C., Cunnold, D., Dlugokencky, E. J., Fraser, P., Gomez-Pelaez, A. J., Goo, T.-Y., Kim, J.-S., Krummel, P., Langenfelds, R., Meinhardt, F., Mukai, H., O’Doherty, S., Prinn, R. G., Simmonds, P., Steele, P., Tohjima, Y., Tsuboi, K., Uhse, K., Weiss, R., Worthy, D., and Nakazawa, T.: Growth Rate, Seasonal, Synoptic, Diurnal Variations and Budget of Methane in the Lower Atmosphere, J. Meteorol. Soc. Jpn., 87, 635-663, 2009b.

Patra, P. K., Houweling, S., Krol, M., Bousquet, P., Belikov, D., Bergmann, D., Bian, H., Cameron-Smith, P., Chipperfield, M. P., Corbin, K., Fortems-Cheiney, A., Fraser, A., Gloor, E., Hess, P., Ito, A., Kawa, S. R., Law, R. M., Loh, Z., Maksyutov, S., Meng, L., Palmer, P. I., Prinn, R. G., Rigby, M., Saito, R., and Wilson, C.: TransCom model simulations of $\mathrm{CH}_{4}$ and related species: linking transport, surface flux and chemical loss with $\mathrm{CH}_{4}$ variability in the troposphere and lower stratosphere, Atmos. Chem. Phys., 11, 12813-12837, https://doi.org/10.5194/acp-11-128132011, 2011.

Patra, P. K., Krol, M. C., Montzka, S. A., Arnold, T., Atlas, E. L., Lintner, B. R., Stephens, B. B., Xiang, B., Elkins, J. W., Fraser, P. J., Ghosh, A., Hintsa, E. J., Hurst, D. F., Ishijima, K., Krummel, P. B., Miller, B. R., Miyazaki, K., Moore, F. L., Mühle, J., O’Doherty, S., Prinn, R. G., Steele, L. P., Takigawa, M., Wang, H. J., Weiss, R. F., Wofsy, S. C., and Young, D.: Observational evidence for interhemispheric hydroxyl-radical parity, Nature, 513, 219-223, 2014.

Peters, W., Krol, M. C., Dlugokencky, E. J., Dentener, F. J., Bergamaschi, P., Dutton, G., van Velthoven, P., Miller, J., Bruh- wiler, L., and Tans, P. P.: Toward regional-scale modeling using the two-way nested global model TM5: Characterization of transport using SF6, J. Geophys. Res., 109, D19314, https://doi.org/10.1029/2004JD005020, 2004.

Peters, W., Krol, M. C., van der Werf, G. R., Houweling, S., Jones, C. D., Hughes, J., Schaefer, K., Masarie, K. A., Jacobson, A. R., Miller, J. B., Cho, C. H., Ramonet, M., Schmidt, M., Ciattaglia, L., Apadula, F., Helta, D., Meinhardt, F., di Sarra, A. G., Piacentino, S., Sferlazzo, D., Aalto, T., Hatakka, J., Strom, J., Haszpra, L., Meijer, H. A. J., van der Laan, S., Neubert, R. E. M., Jordan, A., Rodó, X., Morguí, J. A., Vermeulen, A. T., Popa, E., Rozanski, K., Zimnoch, M., Manning, A. C., Leuenberger, M., Uglietti, C., Dolman, A. J., Ciais, P., Heimann, M., and Tans, P. P.: Seven years of recent European net terrestrial carbon dioxide exchange constrained by atmospheric observations, Glob. Change Biol., 16, 1317-1337, 2010.

Ploeger, F., Abalos, M., Birner, T., Konopka, P., Legras, B., Mueller, R., and Riese, M.: Quantifying the effects of mixing and residual circulation on trends of stratospheric mean age of air, Geophys. Res. Lett., 42, 2047-2054, 2015.

Prather, M., McElroy, M., Wofsy, S., Russell, G., and Rind, D.: Chemistry of the global troposphere: Fluorocarbons as tracers of air motion, J. Geophys. Res., 92, 6579-6613, 1987.

Prather, M. J., Zhu, X., Strahan, S. E., Steenrod, S. D., and Rodriguez, J. M.: Quantifying errors in trace species transport modeling, P. Natl. Acad. Sci. USA, 105, 19617-19621, 2008.

Prather, M. J., Zhu, X., Tang, Q., Hsu, J., and Neu, J. L.: An atmospheric chemist in search of the tropopause, J. Geophys. Res.Atmos., 116, D04306, https://doi.org/10.1029/2010JD014939, 2011.

Prather, M. J., Holmes, C. D., and Hsu, J.: Reactive greenhouse gas scenarios: Systematic exploration of uncertainties and the role of atmospheric chemistry, Geophys. Res. Lett., 39, L09803, https://doi.org/10.1029/2012GL05144, 2012.

Rayner, N. A., Parker, D. E., Horton, E. B., Folland, C. K., Alexander, L. V., Rowell, D. P., Kent, E. C., and Kaplan, A.: Global analyses of sea surface temperature, sea ice, and night marine air temperature since the late nineteenth century, J. Geophys. Res.-Atmos., 108, 4407, https://doi.org/10.1029/2002JD002670, 2003.

Roeckner, E., Brokopf, R., Esch, M., Giorgetta, M., Hagemann, S., Kornblueh, L., Manzini, E., Schlese, U., and Schulzweida, U.: Sensitivity of Simulated Climate to Horizontal and Vertical Resolution in the ECHAM5 Atmosphere Model, J. Climate, 19, 3771-3791, 2006.

Russel, G. and Lerner, J.: A new finite-differencing scheme for the tracer transport equation, J. Appl. Meteorol., 20, 1483-1498, 1981.

Schneider, T., Bischoff, T., and Haug, G. H.: Migrations and dynamics of the intertropical convergence zone, Nature, 513, 4553, 2014

Stiller, G. P., von Clarmann, T., Haenel, F., Funke, B., Glatthor, N., Grabowski, U., Kellmann, S., Kiefer, M., Linden, A., Lossow, S., and López-Puertas, M.: Observed temporal evolution of global mean age of stratospheric air for the 2002 to 2010 period, Atmos. Chem. Phys., 12, 3311-3331, https://doi.org/10.5194/acp12-3311-2012, 2012. 
Stockwell, D. Z. and Chipperfield, M. P.: A tropospheric chemicaltransport model: Development and validation of the model transport schemes, Q. J. Roy. Meteor. Soc., 125, 1747-1783, 1999.

Tiedtke, M.: A Comprehensive Mass Flux Scheme for Cumulus Parameterization in Large-Scale Models, Mon. Weather Rev., 117, 1779-1800, 1989.

Tost, H., Jöckel, P., Kerkweg, A., Sander, R., and Lelieveld, J.: Technical note: A new comprehensive SCAVenging submodel for global atmospheric chemistry modelling, Atmos. Chem. Phys., 6, 565-574, https://doi.org/10.5194/acp-6-565-2006, 2006.

Tost, H., Lawrence, M. G., Brühl, C., Jöckel, P., The GABRIEL Team, and The SCOUT-O3-DARWIN/ACTIVE Team: Uncertainties in atmospheric chemistry modelling due to convection parameterisations and subsequent scavenging, Atmos. Chem. Phys., 10, 1931-1951, https://doi.org/10.5194/acp-101931-2010, 2010.

Tsuruta, A., Aalto, T., Backman, L., Hakkarainen, J., van der LaanLuijkx, I. T., Krol, M. C., Spahni, R., Houweling, S., Laine, M., Dlugokencky, E., Gomez-Pelaez, A. J., van der Schoot, M., Langenfelds, R., Ellul, R., Arduini, J., Apadula, F., Gerbig, C., Feist, D. G., Kivi, R., Yoshida, Y., and Peters, W.: Global methane emission estimates for 2000-2012 from CarbonTracker Europe- $\mathrm{CH}_{4}$ v1.0, Geosci. Model Dev., 10, 1261-1289, https://doi.org/10.5194/gmd-10-1261-2017, 2017.

Valcke, S.: The OASIS3 coupler: a European climate modelling community software, Geosci. Model Dev., 6, 373-388, https://doi.org/10.5194/gmd-6-373-2013, 2013.

Vogelezang, D. H. P. and Holtslag, A. A. M.: Evaluation and model impacts of alternative boundary-layer height formulations, Bound.-Lay. Meteorol., 81, 245-269, 1996.
Wang, K. Y., Pyle, J. A., Sanderson, M. G., and Bridgeman, C.: Implementation of a convective atmospheric boundary layer scheme in a tropospheric chemistry transport model, J. Geophys. Res., 104, 23729-23745, https://doi.org/10.1029/1999JD900383, 1999.

Waugh, D. W. and Funatsu, B. M.: Intrusions into the tropical upper troposphere: Three-dimensional structure and accompanying ozone and OLR distributions, J. Atmos. Sci., 60, 637-653, 2003.

Waugh, D. W., Crotwell, A. M., Dlugokencky, E. J., Dutton, G. S., Elkins, J. W., Hall, B. D., Hintsa, E. J., Hurst, D. F., Montzka, S. A., Mondeel, D. J., Moore, F. L., Nance, J. D., Ray, E. A., Steenrod, S. D., Strahan, S. E., and Sweeney, C.: Tropospheric SF6: Age of air from the Northern Hemisphere midlatitude surface, J. Geophys. Res.-Atmos., 118, 11429-11441, 2013.

Williams, J. E., Boersma, K. F., Le Sager, P., and Verstraeten, W. W.: The high-resolution version of TM5-MP for optimized satellite retrievals: description and validation, Geosci. Model Dev., 10, 721-750, https://doi.org/10.5194/gmd-10-721-2017, 2017.

Wofsy, S. C. and the HIPPO Science Team and Cooperating Modellers and Satellite Teams: HIAPER Pole-to-Pole Observations (HIPPO): fine-grained, global-scale measurements of climatically important atmospheric gases and aerosols, Philosophical Transactions of the Royal Society of London A: Mathematical, Physical and Engineering Sciences, 369, 2073-2086, 2011.

Yin, Y., Chevallier, F., Ciais, P., Broquet, G., Cozic, A., Szopa, S., and Wang, Y.: On biases in atmospheric CO inversions assimilating MOPITT satellite retrievals, Atmos. Chem. Phys. Discuss., https://doi.org/10.5194/acp-2017-166, 2017. 